INFLUENCIA DEL COEFICIENTE ESTRUCTURAL DE UNA BASE RECICLADA CON CEMENTO SOBRE LA DEFORMACION PERMANENTE EN LA SUBRASANTE - UNA APROXIMACIÓN CON EL METODO SUDAFRICANO

PRESENTADO POR:

GINA FRANCESCA GRAVIER SANTANA. CÓDIGO: 506648.

\title{
Trabajo De Grado
}

Director:

Ingeniero Mario Alexander Castañeda.

Co-director:

Ingeniero Camilo Andrés Muñoz.

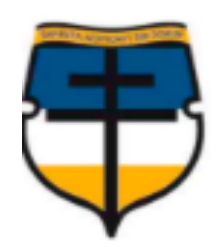

UNIVERSIDAD CATÓLICA DE COLOMBIA.

FACULTAD DE INGENIERÍA.

PROGRAMA DE INGENIERÍA CIVIL. BOGOTÁ D.C. 


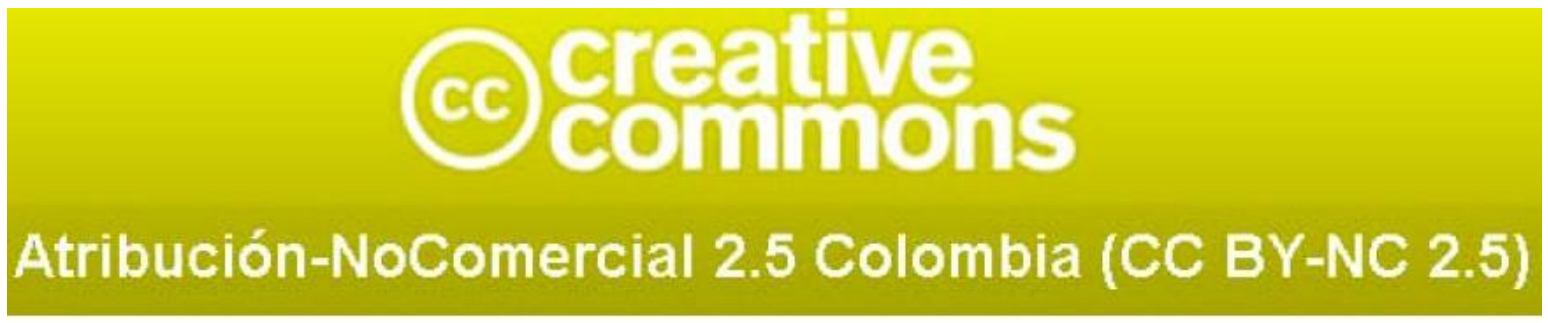

La presente obra está bajo una licencia:

Atribución-NoComercial 2.5 Colombia (CC BY-NC 2.5)

Para leer el texto completo de la licencia, visita:

http://creativecommons.org/licenses/by-nc/2.5/co/

Usted es libre de:

Compartir - copiar, distribuir, ejecutar y comunicar públicamente la obra

hacer obras derivadas

Bajo las condiciones siguientes:

(i)

Atribución - Debe reconocer los créditos de la obra de la manera especificada por el autor o el licenciante (pero no de una manera que sugiera que tiene su apoyo o que apoyan el uso que hace de su obra).

No Comercial - No puede utilizar esta obra para fines comerciales. 


\section{CONTENIDO}

pág.

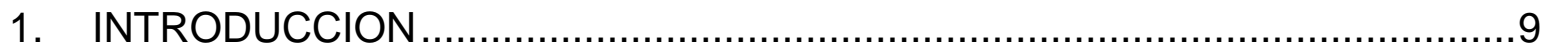

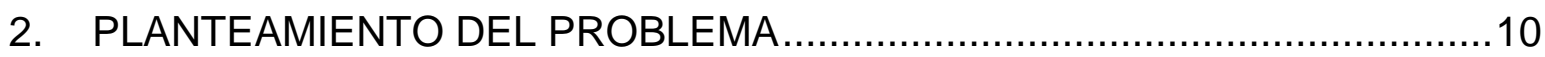

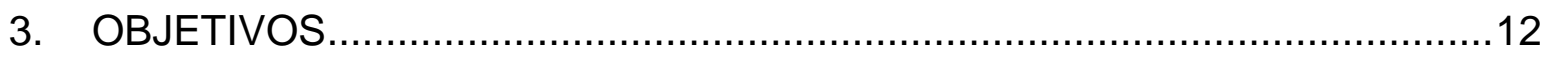

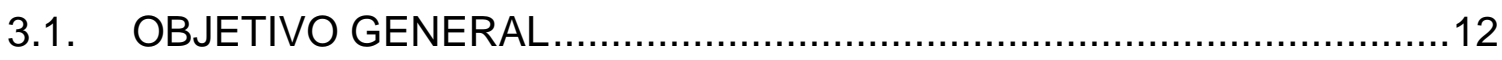

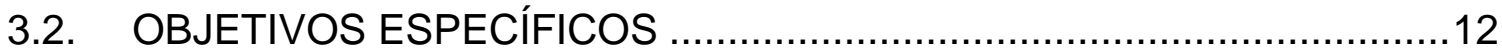

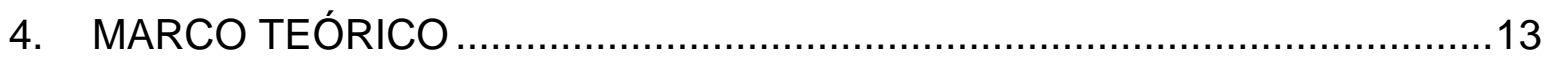

4.1. DISEÑO DE PAVIMENTOS FLEXIBLES AASTHO - 93......................13

4.1.1.1. Ecuaciones de diseño para pavimentos flexibles..........................13

4.1.1.2. Comportamiento de los pavimentos..........................................14

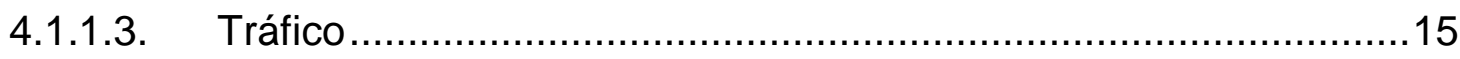

4.1.1.4. Suelo de fundación .............................................................15

4.1.1.5. Materiales de construcción ....................................................16

4.1.1.6. Medio ambiente .............................................................. 17

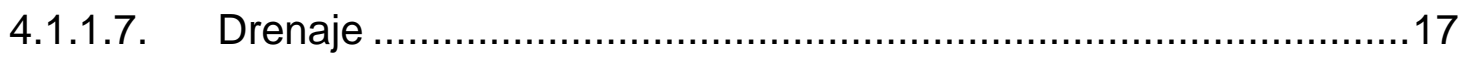

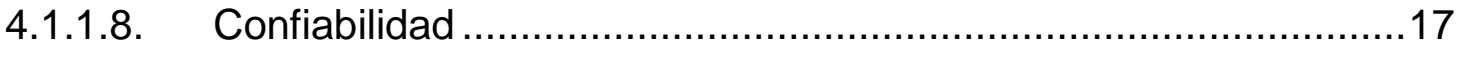

4.2. DISEÑO DE PAVIMENTOS SUDAFRICANOS …..............................19

4.2.1. Estimacion de la capacidad estructural pavimento flexible ...............20

4.2.2. Fatiga de asfalto de mezcla en caliente …..................................20

4.2.3. Deformación permanente de la capa granular y de la subbase .......21

4.2.4. Deformación permanente de subrasante ......................................22

4.3. PROGRAMA DE DISEÑO DE PAVIMENTOS DEPAV.........................24

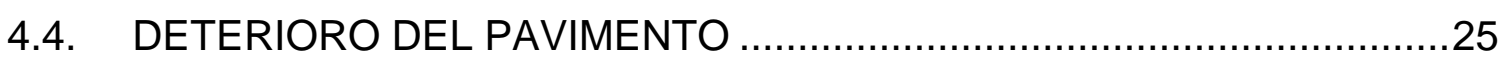


4.4.1. Mantenimiento y rehabilitación del pavimento ................................26

4.4.2. Opciones de rehabilitación de un pavimento ..................................27

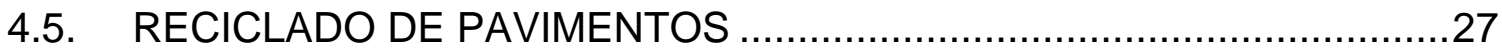

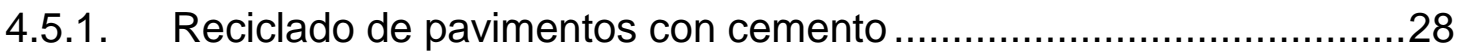

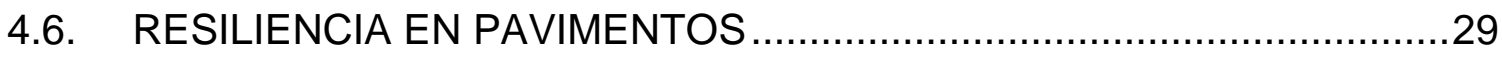

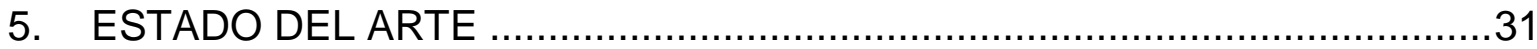

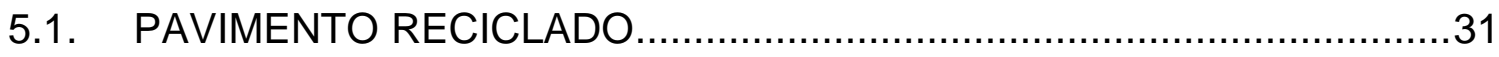

5.2. RELACION MODULO RESILIENTE - CAPA CEMENTADA - RAP .......33

5.3. DISEÑO DE PAVIMENTOS ASFALTICOS METOLOGIA AASHTO Y

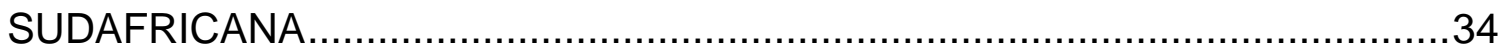

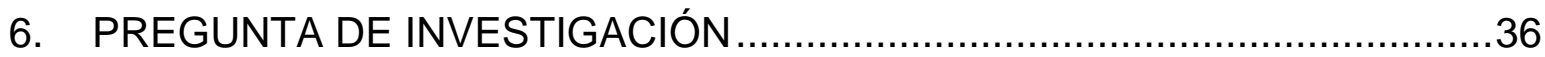

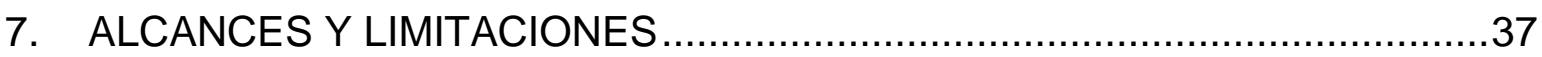

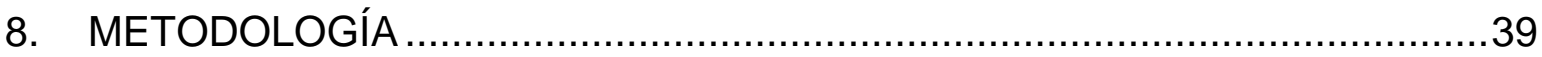

8.1. MATERIALES CONTEMPLADOS PARA DISEÑO DEL PAVIMENTO....40

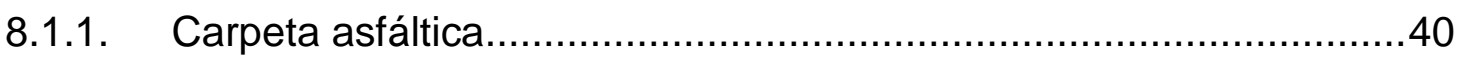

8.1.2. Base reciclada con cemento ……............................................

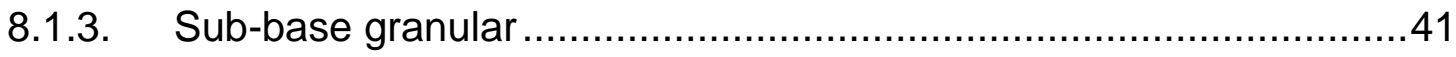

8.2. DISEÑO PAVIMENTO (METODOLOGÍA AASHTO-93) .......................42

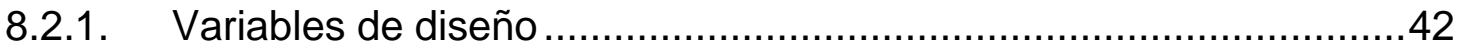

8.2.2. Caculo numero estructural requerido para la estructura...................43

8.2.3. Caculo numero estructural disponible por la estructura....................44

8.2.4. Calculo espesor ajustado de sub-base granular $(D 3 *) \ldots \ldots \ldots \ldots \ldots \ldots . . .45$

8.3. MODELACIÓN EN EL SOFTWARE DEPAV ....................................45

8.4. ANÁLISIS DEFORMACIÓN PERMANENTE DE LA SUBRASANTE

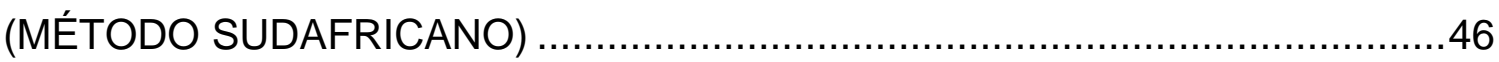


9. CALCULOS Y RESULTADOS

9.1. DETERMINACIÓN DEL NÚMERO ESTRUCTURAL REQUERIDO (METODOLOGÍA AASHTO-93) .

9.2. DETERMINACIÓN NÚMERO ESTRUCTURAL (METODOLOGÍA AASHTO-93) .47

9.3. CALCULO ESPESOR AJUSTADO DE SUB-BASE GRANULAR $(D 3 *) .49$

9.4. MODELACIÓN EN EL SOFTWARE DEPAV... .50

9.5. ANÁLISIS DE LA DEFORMACIÓN PERMANENTE DE LA SUBRASANTE (MÉTODO SUDAFRICANO) .58

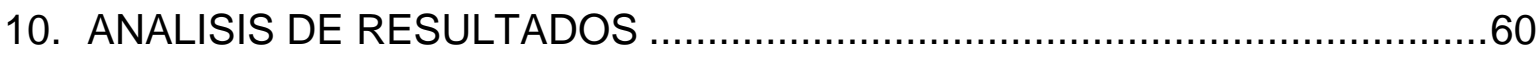

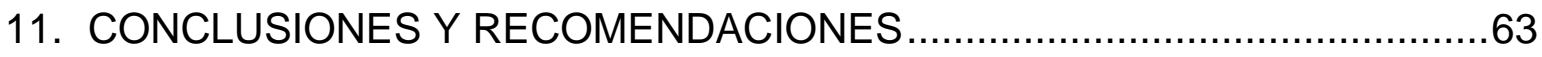

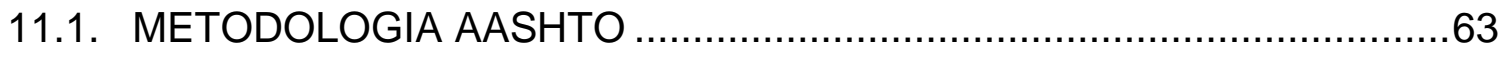

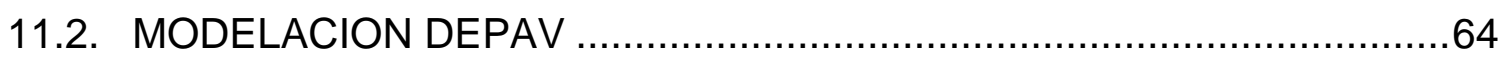

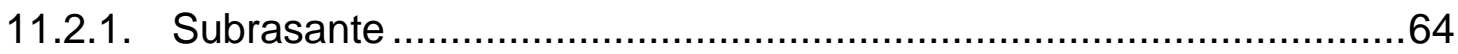

11.2.2. Base reciclada con cemento (BRC) ...............................................64

11.3. DEFORMACION PERMANENTE DE LA SUBRASANTE -

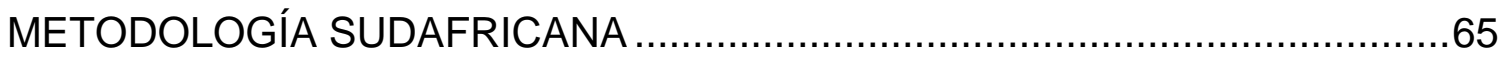

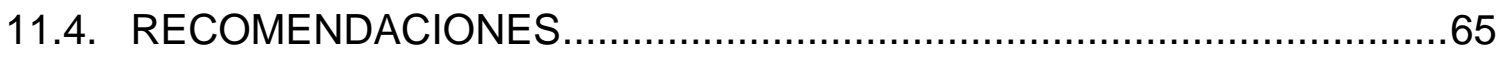

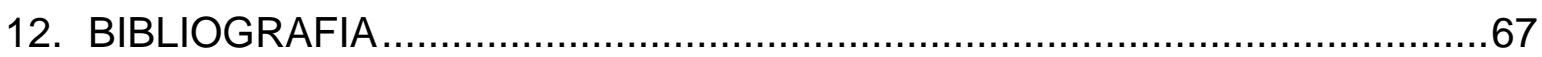




\section{LISTA DE IMAGENES}

Imagen 1. Indicadores de deterioro de pavimentos …......................................25

Imagen 2. Calidad del rodado en función del mantenimiento y rehabilitacón

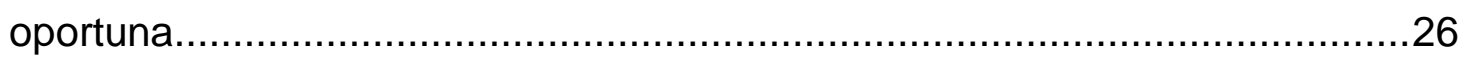

Imagen 3. Deformacion acumulada despues de $\mathrm{N}$ ciclos. ..................................30

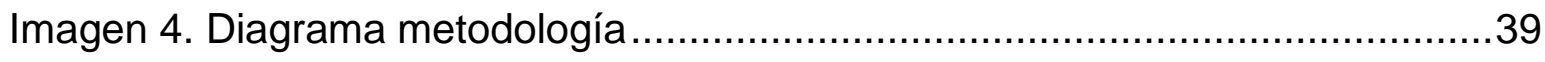

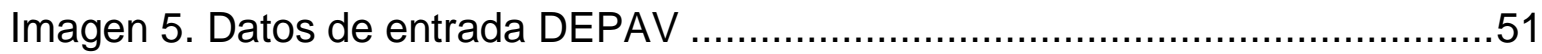

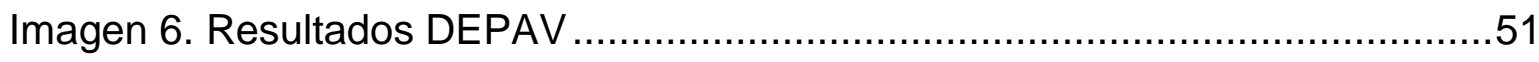




\section{LISTA DE TABLAS}

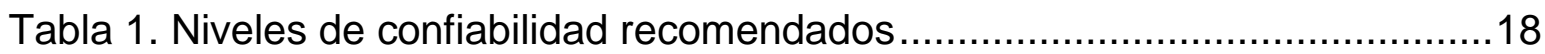

Tabla 2. Desviación estándar normal (Zr) para niveles de confiabilidad $(\mathrm{R})$..........18

Tabla 3. Módulos elásticos para capas de carpeta asfáltica ..................................21

Tabla 4. Modulos elásticos para capas granulares ...........................................22

Tabla 5. Clasificacion de subrasante en función de CBR ......................................22

Tabla 6. Modulos elásticos para capas de subrasante .......................................23

Tabla 7. Constantes usasdas en modelo de daño .................................................24

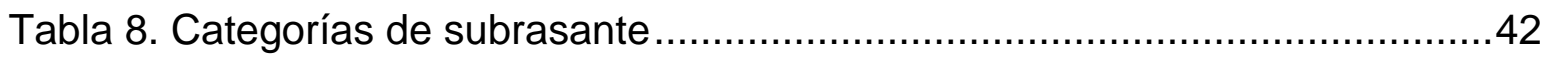

Tabla 9. Consideraciones fijas para cálculo de (SN0) ….................................44

Tabla 10. Números estructurales requeridos (SN0) .......................................47

Tabla 11. Altura final en $\mathrm{cm}$ de la SBG para SN requerido con $\mathrm{a} 2=0,12 \ldots \ldots \ldots \ldots . .49$

Tabla 12. Altura final en $\mathrm{cm}$ de la SBG para SN requerido con a2 $=0,17 \ldots \ldots \ldots \ldots . . .50$

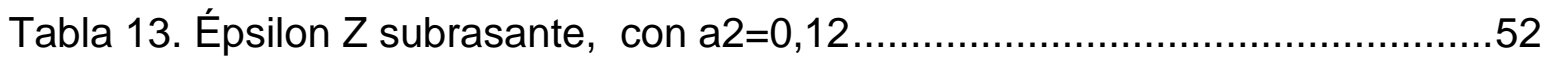

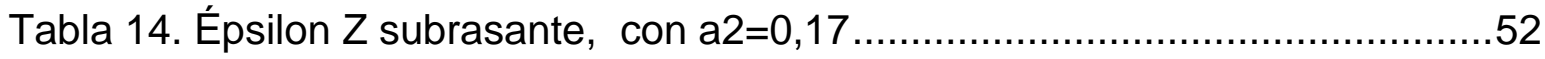

Tabla 15. Sigma Z (kg/cm2) subrasante, con a2 $=0,12 \ldots \ldots \ldots \ldots \ldots \ldots \ldots \ldots \ldots \ldots \ldots \ldots . . .53$

Tabla 16. Sigma $Z(\mathrm{~kg} / \mathrm{cm} 2)$ subrasante, con a2 $=0,17 \ldots \ldots \ldots \ldots \ldots \ldots \ldots \ldots \ldots \ldots \ldots \ldots . . .54$

Tabla 17. Sigma $T(\mathrm{~kg} / \mathrm{cm} 2)$ en base reciclada con cemento, con $\mathrm{a} 2=0,12 \ldots \ldots \ldots . .55$

Tabla 18. Sigma $T(\mathrm{~kg} / \mathrm{cm} 2)$ en base reciclada con cemento, con a2 $=0,17 \ldots \ldots \ldots . .55$

Tabla 19. Epsilon $T$ en base reciclada con cemento, con $a 2=0,12 \ldots \ldots \ldots \ldots \ldots \ldots \ldots . .56$

Tabla 20. Epsilon $T$ en base reciclada con cemento, con a2 $=0,17 \ldots \ldots \ldots \ldots \ldots \ldots \ldots . .57$

Tabla 21. Valores de N_PD (millones), con a2 $=0,12 \ldots \ldots \ldots \ldots \ldots \ldots \ldots \ldots \ldots \ldots \ldots \ldots \ldots . . .58$

Tabla 22. Valores de N_PD (millones), con a2 $=0,17 \ldots \ldots \ldots \ldots \ldots \ldots \ldots \ldots \ldots \ldots \ldots \ldots \ldots . . .58$ 


\section{LISTA DE GRAFICAS}

Gráfica 1. Deformación vertical en la subrasante. .............................................53

Gráfica 2. Esfuerzo de compresión en subrasante. .........................................54

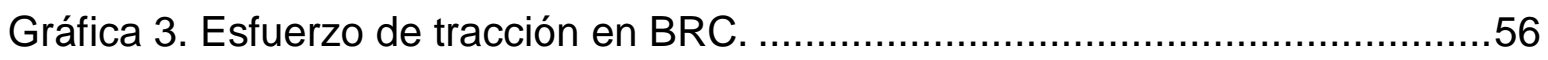

Gráfica 4. Deformacion de tracción en BRC. .................................................57

Gráfica 5. N_PD vs Deformacion vertical subrasante $\left(a \_2=0,12\right) \ldots \ldots \ldots \ldots \ldots \ldots \ldots . . . . .59$

Gráfica 6. N_PD vs Deformacion vertical subrasante $($ a_2 $2=0,17) \ldots \ldots \ldots \ldots \ldots \ldots \ldots . . . . .59$ 


\section{INTRODUCCION}

La estructura de un pavimento se diseña para que durante su vida útil pueda soportar eficientemente cargas de tránsito que generan ciclos de carga y descarga en el pavimento, por tal razón es fundamental que el diseñador de un pavimento tenga a disposición, no solo la información de los niveles de tránsito esperados para la vía, sino también las caracterizaciones - mediante ensayos de laboratorio - de los diferentes materiales considerados, o disponibles, para el diseño en cuestión.

Uno de los indicadores del comportamiento mecánico de un pavimento es el módulo resiliente (Mr), propiedad que permite estimar la capacidad de recuperación en la zona elástica que tiene un material bajo la aplicación de cargas cíclicas, y su determinación permite al diseñador la posibilidad de utilizar herramientas de cálculo y diseño donde se consideran los diferentes fenómenos producidos en los materiales durante su uso, permitiendo acercar el diseño a las condiciones de operación del pavimento.

En el país, y a nivel mundial, existe un interés importante por mitigar los impactos ambientales generados por los diferentes sectores de la economía, siendo uno de ellos el de la construcción con la generación de residuos. Como parte de este propósito, en la ciudad de Bogotá el material bituminoso retirado de las capas asfálticas deterioradas se está reutilizando como bases o sub-bases mejoradas de nuevos pavimentos, motivo por el cual surge la necesidad de analizar las propiedades mecánicas de estas capas de pavimento.

En consideración con la presente investigación se busca evaluar la influencia del coeficiente estructural de una base reciclada con cemento, en la deformación permanente de la subrasante y validar la aplicación del modelo de daño del método Sudafricano. 


\section{PLANTEAMIENTO DEL PROBLEMA}

Con base en la literatura consultada se encontró que el INVIAS hace referencia a manuales y experiencias extranjeras, entre las que se encuentran las Sudafricanas, para hacer las diferentes recomendaciones respecto a los parámetros de diseño para pavimentos reciclados. En éste caso particular en lo correspondiente a los valores de coeficientes estructurales de cada una de sus capas, el INVIAS sugiere dos valores típicos para el coeficiente estructrual de una base reciclada con cemento $\left(a_{2}\right)$ en función de su resistencia a la compresión inconfinada. No obstante es límitada la informacion respecto a cómo interfiere el usar uno u otro valor en el diseño y cómo ésto afecta el comportamiento de la estructura durante su vida útil.

A partir de lo descrito previamente se definió como problema central la falta de informacion respecto a la influencia de la variacion del coeficiente estructural de una base reciclada en frío con RAP y cemento, sobre el valor de la deformación permanente de la subrasante. En general se evidencia poco interés por estudiar de forma particular las características y comportamientos de los materiales reciclados, a pesar de ser ampliamente conocido que el diseño de una via es determinado por el módulo resiliente del material. Se pudieron identificar algunas situaciones que han contribuido a la formación de este problema, sus causas y efectos se relacionan a continuación:

Se identifico una falta de actualización en la normatividad para la construcción de vías en el país donde se incluyan en su totalidad los nuevos materiales y estructuras de pavimentos utilizados en la actualidad en concordancia con el desarrollo del sector de la construcción, en especial respecto al uso de pavimento reciclado con cemento. Esta situación se puede percibir al revisar algunos documentos vigentes del INVIAS como: "Especificaciones generales de construcción de carreteras" expedido en el año 2013 que en en lo concerniente al tema de reciclado, solo cuenta con el Articulo 461 correspondiente al reciclado de pavimento asfaltico en frio en el lugar empleando ligantes bituminosos, y el Articulo 462 respecto al reciclado de pavimento asfaltico en planta y en caliente. El otro documento vigente y relevante para el tema es la "Guía metodológica para el diseño de obras de rehabilitación de pavimentos asfálticos de carreteras" expedida en el 2008 por el INVIAS, en éste se trata brevemente el tema de reciclado de pavimento, tocando un poco lo concerniente al aporte estructural que se busca con el uso del cemento en dicho procedimiento. Sin embargo no aborda nada respecto a los temas de diseño, resistencia o modulo resiliente.

Tambien se evidencia que la falta información técnica oficial respecto a las mezclas RAP-Cemento puede deberse a que es reciente el interés del Gobierno Distrital y Nacional en temas como de uso de materiales reciclados en construccion del 
impacto ambiental generado por el desarrollo acelerado del sector de la construcción y su mitigacion. Apenas en el año 2012 para Bogotá se generó la resolución 1115 expedida por la Secretaria Distrital de Ambiente que hizo obligatorio que los constructores utilizaran en sus obras residuos de construcción y demolición, y solo hasta el año 2017 el Gobierno Nacional a través del Ministerio de Ambiente y Desarrollo Sostenible expide la Resolución 472 de 2017 en la cual establece los lineamientos y obligatoriedad en todo el territorio Nacional del aprovechamiento de los residuos de construcción.

Con base en lo mencionado previamente se concluye que es escaso el conocimiento a nivel nacional en cuanto al comportamiento mecanico que pueden tener las mezclas cementadas especialmente con RAP, asi como sus ventajas, desventajas y usos que se les podría dar, debido principalmente a que no se cuenta con una norma especifica que contenga entre su información técnica los rangos de valores para sus parámetros especificos como resistencia o modulo resiliente, que permitan diseñar correctamente estructuras viales con este material. De esta manera se puede decir que actualmente el diseño de vías con material asfáltico reciclado se está realizando bajo guías o manuales que no consideran experiencias locales, simples estimaciones, y no con base en documentos formales con resultados de estudios reales producto de ensayos en laboratorio o en campo. Lo que conlleva a una alta incertidumbre respecto a la respuesta real del material ante el tránsito que soportará durante su vida útil, pudiendo ocasionar un deterioro prematuro de algunos de estos pavimentos a causa de una respuesta mecánica inesperada

Por lo anterior, en ésta investigación se pretende obtener valores de esfuerzos y deformaciones en los puntos críticos, de pavimentos con base reciclada con RAPCEMENTO, que una vez sean analizados permitan estimar unos resultados más cercanos a la realidad en cuanto a la respuesta de éste material reciclado ante el tránsito que soportaria durante su vida útil, permitiendo también un acercamiento al comportamiento de la subrasante en dicho diseño. Asi mismo se busca brindar información relevante y que pueda ser usada como referencia en futuras investigaciones en el tema de estudio tanto en Colombia como en otros países. 


\section{OBJETIVOS}

\subsection{OBJETIVO GENERAL}

Determinar la influencia del coeficiente estructural de una base reciclada con cemento sobre la deformación permanente en la subrasante, y analizar su compatibilidad con el método Sudafricano.

\subsection{OBJETIVOS ESPECÍFICOS}

Diseñar bajo la metodología AASHTO-93, dos estructuras de pavimento asfaltico con base reciclada con cemento, usando los dos coeficientes estructurales $\left(a_{2}\right)$ recomendados en la "Guía para el diseño de rehabilitación de pavimentos asfálticos" del INVIAS".

Establecer la incidencia en los diseños de pavimentos, de la variación en valores de coeficiente estructural $a_{2}$, modulo resiliente de la subrasante y del nivel de transito de diseño mediante la realización de doce combianciones posibles para cada coeficiente estructural.

Modelar en el software DEPAV las estructuras de pavimento diseñadas por AASHTO, para obtener los esfuerzos y deformaciones correspondientes en cada capa.

Evaluar la deformación permanente de la subrasante mediante la función de transferencia del modelo Sudafricano para subrasante, usando los valores de deformación vertical obtenidos del software DEPAV.

Verificar el esfuerzo de tracción generado en la parte inferior de la capa de base reciclada con cemento a través de los resultados del software DEPAV. 


\section{MARCO TEÓRICO}

\subsection{DISEÑO DE PAVIMENTOS FLEXIBLES AASTHO - 93}

Esta guia proporciona un conjunto de procedimientos y recomendaciones para ser usados en el diseño y rehabilitación de pavimentos, teniendo en cuenta que el usuario debe adaptar las experiencias locales al uso de la guia. Tales recomendaciones incluyen la determinacion del espesor total de la estructura del pavimento, así como el espesor de los componentes estructurales individuales (American Association of State Highway and Transportation Offcials, 1993)

\subsubsection{Consideraciones de diseño}

Este método considera para el diseño de una estructura una variedad de factores, entre los de mayor importancia estan: tráfico, suelo de fundación, materiales de construcción, medio ambiente, drenaje y confiabilidad.

\subsubsection{Ecuaciones de diseño para pavimentos flexibles}

Las ecuaciones basicas de diseño usadas son: Para el calculo del numero estructural requerido (SN).

Ecuación 1

$\log N_{80 k N}=Z r \times S o+9.36 \log (S N+1)-0.20+\left[\frac{\log \left(\frac{\Delta P S I}{4.2-1.5}\right)}{0.40+\frac{1094}{(S N+1)^{5.19}}}\right]+2.32 \log M_{r}-8.07$

Donde:

$\quad \mathrm{N} 80 \mathrm{kN}$ : $\quad \quad \quad \quad \quad \quad \quad$ úmero acumulado de ejes equivalentes de $80 \mathrm{kN}$ en el carril de diseño durante el período de diseño

Zr, So: $\quad$ Parámetros de confiabilidad en el diseño 
SN : $\quad$ Número estructural

DPSI : $\quad$ Pérdida de serviciabilidad, DPSI

Mr: $\quad$ Módulo resiliente de la subrasante, en psi

Para el cálculo del numro estructural disponible por el diseño propuesto:

$$
S N=a_{1} * D_{1}+a_{2} * D_{2} * m_{2}+a_{3} * D_{3} * m_{3} \quad \text { Ecuación } 2
$$

Donde:

$a_{i}: \quad$ Coeficiente estructural de capa i

$D_{i}: \quad$ Espesor de capa i (pulgadas)

$m_{i}: \quad$ Coeficiente de drenaje de la capa i

\subsubsection{Comportamiento de los pavimentos}

El comportamiento estructural de un pavimento se relaciona con su condición física, esto es, con la ocurrencia de agrietamientos, fallas, peladuras, $u$ otras situaciones que podrían afectar exclusivamente la capacidad de soporte de la estructura del pavimento o en todo caso, requerir mantenimiento.

El comportamiento funcional de un pavimento se refiere a que tan bien sirve el pavimento al usuario, es decir que la transitabilidad es la característica predominante y para calificar el confort de la' transitabilidad" se desarrolló el concepto de "serviciabilidad-comportarniento", concepto expresado en términos del índice de serviciabilidad presente (PSI-Pavement Serviciability Index)) el cual es obtenido de las medidas de rugosidad y daños, por ejemplo agrietamiento, parchados y profundidad del ahuellamiento, en un momento particular durante la vida de servicio del pavimento.

La escala para el PSI va de 0 a 5 , con el valor de 5 representando al índice de serviciabilidad más alto. Para el diseño es necesario seleccionar ambos indices de 
serviciabilidad inicial (inmediatamente después de la construcción) y terminal (nivel mas bajo aceptable antes de requerir una rehabilitación).

A partir de resultados experimentales en pavimentos flexibles se recomienda un índice de serviciabilidad incial de 4,2 y de serviciabilida final de 2,5 ó 3,0 para carreteras principales y de 2,0 para carreteras con una clasificación menor.

Es importante tener en cuenta que los factores que influyen de manera importante en la pérdida de serviciabilidad de un pavimento $\triangle P S I$ son: tráfico, edad y medio ambiente (American Association of State Highway and Transportation Offcials, 1993).

\subsubsection{Tráfico}

El efecto dañino del paso de un eje de cualquier masa puede ser representado por un número de cargas por eje simple equivalente de 18-kip ó ESAL (Equivalent Single Axle Load). Para las ecuaciones de diseño, la determinación del ESAL de diseño es un aspecto muy importante.

Por lo anterior es necesario convertir el flujo de tráfico en un número equivalente de cargas por eje simple de 18 kip y sumarlos durante todo el período de diseño, que usualmente varia entre 10 a 20 años.

Es importante una información confiable concerniente a los ESAL acumulados para la determinación de los requerimientos de la estructura del pavimento, tanto para construcciones nuevas como para rehabilitaciones, por ello es vital un monitoreo continuo del tráfiro en rutas seleccionadas para comparar las cargas del tráfico previstas con las reales, con en el objetivo de generar diseños confiables.

\subsubsection{Suelo de fundación}

La propiedad definitiva usada para caracterizar el suelo de fundación es el modulo resiliente (MR), el cual puede ser determinado directamente en la subrasante o por medio del ensayo AASHTO T 274. El valor de modulo resiliente reemplaza el valor de soporte del suelo que era utilizado anteriormente en las ecuaciones de diseño.

Debido a que muchos laboratorios no cuentan con equipos necesarios para ejecutar ensayos para la determinación del modulo resiliente, se cuenta con ecuaciones de correlacion de diferentes agencias para estimar el MR a partir de los ensayos de $\mathrm{CBR}$, entre las cuales se presenta la siguiente ecuación: 


$$
M R(P S I)=1500 * C B R
$$

Ecuación 3

\subsubsection{Materiales de construcción}

Los pavimentos flexibles generalmente consisten de un suelo de fundación preparado (subrasante), y a continuación las capas de sub base, base y superficie de rodadura. En algunos casos la sub-base y/o base se estábilizan para- máximizar el uso de los materiales locales.

Sub-base: Capa granular compactada que se ubica entre la subrasante y la capa de base. Sus requrimientos de especificación en resistencia, plasticidad y gradación son menos estrictos que los de la base, y a su vez debe ser de mejor calidad que la subrasante. Cuando la subrasante es de buena calidad, frecuentemente se omite la sub-base.

En el diseño de pavimento, la sub-base necesita un coeficiente de capa $\left(a_{3}\right)$ para convertir su espesor actual a un número estructural (SN).

Base: Capa granular compactada ubicada inmediatamente debajo de la carpeta de rodadura y construida sobre la sub-base (si la hay) o subrasante. Sus requerimientos de especificación en resistencia, plasticidad y gradación son mas estrictos que los de la sub-base, y a su vez debe ser de mejor calidad que la subrasante. Puede usarse sin tratar o tratada con aditivos estabilizantes como por ejemplo cemento, asfalto, cal, cemento de cenizas volantes y cal de cenizas volantes.

En el diseño de pavimento, la base necesita un coeficiente de capa $\left(a_{2}\right)$ para convertir su espesor actual a un número estructural (SN).

Capa superficial: Corresponde a una estructura flexible construida sobre la base, y compuesta por agregados y ligante bituminoso. Esta capa debe resistir las fuerzas abrasivas del trafico, restringir la penetración de agua en las capas del pavimento, brindar una superficie de transito lisa y uniforme.

La capa de rodadura debe ser apropiadamente compactada, de no ser asi se presentaran daños que reducen la vida y el comportamiento del pavimento, tales como ahuellamiento, fallas estructurales por la infinfiltración agua superfial, y agrietamientos en la capa.

En el diseño de pavimento, la capa superficial requiere un coeficiente de capa $\left(a_{1}\right)$ para convertir su espesor actual a un número estructural (SN). 
Los coeficientes de las capas de sub-base granular $\left(a_{3}\right)$, base $\left(a_{2}\right)$ y capa superficial $\left(a_{1}\right)$ se determinan a partir de los nomogramas detallados en la guía de diseño, con base en los parámetros de modulo elástico.

\subsubsection{Medio ambiente}

Los principales factores ambientales que afectan una estructura de pavimento son las lluvias y la temperatura.

La temperatura afecta: las propiedades de fluencia del concreto asfáltico, los esfuerzos térmicos inducidos en el concreto asfáltico, la expansión y contracción del concreto de cemento portland y el hielo y deshielo del terreno de fundación.

Las lluvias afectan las propiedades de la estructura de pavimento y del suelo de cimentación, en el caso de que se infiltren.

\subsubsection{Drenaje}

Parametro de alta importancia en el diseño y contruccion de un pavimento, ya que un mal drenaje de agua lleva a un deterioro prematuro de su estructura y generando algunos fenómenos no deseaos como: reducción de la resistencia de los materiales granulares sin cohesion, reducción de la resistencia de la subrasante, formación de bombeo y agrietamiento de las bermas.

Para el diseño de pavimento con la Guia, el efecto del drenaje sobre el comportamiento de la estructura se considera con lamodificación de los coeficientes estructurales multiplicándolos por un factor determinado en función de las caracteristicas del drenaje, es decir en cuanto tiempo tarda el agua en ser evacuada de la superficie de la estructura y en función del porcentaje de tiempo en el año que la estructura estará expuesta a un nivel de humedad. Este factor varía entre 0,4 y 1,2 .

\subsubsection{Confiabilidad}

Corresponde a la probabilidad de que un pavimento cumpla la función prevista durante su tiempo de diseño y bajo las condiciones encontradas durante la operación. Dicha probabilidad es recomendado según la clasificación funcional de la via, es decir si se trata de una autopista, un arteria principal, una colectora o una lucal, y también teniendo en cuenta si se trata de una via urbana o rural. 
El nivel de confiabilidad $(\mathrm{R})$ del proceso de diseño-comportamiento se expresa como porcentaje y para un determinado nivel de confiabilidad corresponde un valor $Z_{r}$ de desviación estándar normal que se debe considerar en la ecuación básica de diseño. En la Tabla 2 se encuentran los $Z_{r}$ correspondientes para unos niveles seleccionados de confiabilidad.

Tabla 1. Niveles de confiabilidad recomendados

\begin{tabular}{|l|c|c|}
\hline \multirow{2}{*}{$\begin{array}{c}\text { Clasificación funcional de } \\
\text { la via }\end{array}$} & \multicolumn{2}{|c|}{ Nivel recomendado de confiabilidad (\%) } \\
\cline { 2 - 3 } & Urbana & Rural \\
\hline Autopistas & $85-99.9$ & $80-99.9$ \\
\hline Arterias principales & $80-99$ & $75-95$ \\
\hline Colectoras & $80-95$ & $75-95$ \\
\hline Locales & $50-80$ & $50-80$ \\
\hline
\end{tabular}

Fuente: (American Association of State Highway and Transportation Offcials, 1993)

Tabla 2. Desviación estándar normal (Zr) para niveles de confiabilidad (R)

\begin{tabular}{cc}
\hline $\begin{array}{l}\text { Confiabilidad, } \\
\text { R (\%) }\end{array}$ & $\begin{array}{c}\text { Desviación Estandar } \\
\text { Normal, ZR }\end{array}$ \\
\hline 50 & -0.000 \\
60 & -0.253 \\
70 & -0.524 \\
75 & -0.674 \\
80 & -0.841 \\
85 & -1.037 \\
90 & -1.282 \\
91 & -1.340 \\
92 & -1.405 \\
93 & -1.476 \\
94 & -1.555 \\
95 & -1.645 \\
96 & -1.751 \\
97 & -1.881 \\
98 & -2.054 \\
99 & -2.327 \\
99.9 & -3.090 \\
99.99 & -3.750 \\
\hline
\end{tabular}

Fuente: (American Association of State Highway and Transportation Offcials, 1993) 
Otro valor necesario para la ecuación básica de diseño corresponde a la desviación estándar total $\left(S_{0}\right)$ cuyo valor está entre 0,40 y 0,50 para pavimentos flexibles, y que depende de la variacion en la predicción del comportamiento del pavimento y en la estimación del tráfico.

\subsection{DISEÑO DE PAVIMENTOS SUDAFRICANOS}

El Manual de Ingeniería de Pavimentos de Sudáfrica (SAPEM) es un manual de referencia para todos los aspectos de la ingeniería de pavimentos. SAPEM es una guía de mejores prácticas que proporciona detalles sobre diferentes referencias $y$, cuando es necesario, proporciona pautas sobre su uso apropiado.

El diseño del pavimento con este manual cubre muchos aspectos del diseño del pavimento, incluidas las consideraciones de diseño, la estimación del tráfico de diseño, la investigación del pavimento y los procesos de diseño, la estimación de la capacidad estructural y el software disponible para el diseño del pavimento.

El propósito de los métodos de diseño de pavimento estructural es proporcionar un método para la estimación imparcial de la capacidad estructural de opciones de diseño alternativas, con el objetivo de seleccionar la opción más económica y que satisfaga la demanda de tráfico. El objetivo del diseño de pavimentos Sudafricanos es proteger, y mejorar la capacidad de carga del material de subrasante para que el pavimento cumpla con el objetivo de servicio durante el período de diseño.

El diseño esta basado en la determinación de rigideces, deflexiones y esfuerzos en las diferentes capas de una estructura vial, para estimar el tipo de falla que se puede presentar y en donde.

Entre los aspectos de diseño considerados se encuentran: la detrminacion de la categoría de carretera, la capacidad estructural de diseño, y la estrategia de mantenimiento y rehablitacion de la carretera (ciclo de vida). Es decir que para el diseño de una estructura nueva se tienen en cuenta los siguientes componentes: Investigacion detallada del trafico y estimación del trafico de diseño, materiales, y consideraciones ambientales y practicas (South Afrian National Roads Agency LTD, 2013). 


\subsubsection{Estimacion de la capacidad estructural pavimento flexible}

El método de diseño mecanicista-empírico de Sudáfrica (SAMDM) ampliamente usado en el sur de Africa, cuenta con valores de entrada típicos de modulo resiliente y resistencia para materiales de construcción de carreteras en Sudáfrica. Cuenta con una serie de modelos de daño calibrados para los principales grupos de materiales usados en carreteras en Sudafrica. Los modelos de daños previstos son:

Fatiga de asfalto de mezcla en caliente

- Fatiga de capas de superficie delgadas (<50 mm de espesor): de forma continua y con separación

- Fatiga de capas de base gruesas (> $75 \mathrm{~mm}$ de espesor)

Base granular independiente y capa de subbase

- deformación permanente

Capas de base y subbase cementadas

- Fracaso aplastante

- Fatiga efectiva

- Deformación permanente

Deformación permanente de subrasante

\subsubsection{Fatiga de asfalto de mezcla en caliente}

En el SAMDM, las capas superficiales de asfalto solo se analizan en busca de fatiga. Se supone que las grietas comienzan en la parte inferior de la capa y se propagan hasta la superficie. La capacidad estructural, o vida de fatiga determinada representa la superficie de agrietamiento sobre un área definida de la carretera. Esta área depende de la confiabilidad asignada a la categoría de carretera. 
En la Tabla 3 se muestran los módulos elásticos para capas de rodadura delgadas (generalmente menos de $50 \mathrm{~mm}$ de espesor) de forma continua y graduada.

Tabla 3. Módulos elásticos para capas de carpeta asfáltica

\begin{tabular}{|c|c|c|}
\hline Code & $\begin{array}{c}\text { Depth }(\mathbf{d}) \text { Below } \\
\text { Surface }(\mathbf{m m})\end{array}$ & $\begin{array}{c}\text { Modulus } \\
\text { (MPa) }\end{array}$ \\
\hline $\mathrm{AG}^{1}$ & $\leq 50$ & 3000 \\
\hline \multirow{3}{*}{$\mathrm{BC}^{2}$} & $\leq 100$ & 4000 \\
\cline { 2 - 3 } & $100<\mathrm{d} \leq 150$ & 5000 \\
\cline { 2 - 3 } & $150<\mathrm{d} \leq 200$ & 6000 \\
\cline { 2 - 3 } & $200<\mathrm{d} \leq 250$ & 7000 \\
\hline
\end{tabular}

Fuente: (South Afrian National Roads Agency LTD, 2013).

La relación de Poisson generalmente se supone entre 0,4 y 0,44 , con 0,44 como valor recomendado.

Las capas de asfalto se modelan como una capa ligada, que se dobla bajo la aplicación de carga. Esto induce grietas en el fondo de la capa, que se propagan hasta la superficie La función de daño usa la tensión de tracción horizontal en la parte inferior de la capa, que representa la resistencia a la formación de grietas.

La funcion de transferencia usada tiene en cuenta si es una capa de superficie delgada $(<50 \mathrm{~mm}$ ) o una base de asfalto gruesa ( $>75 \mathrm{~mm}$ ), asi como una constante en función de la confiabilidad de la carretera.

\subsubsection{Deformación permanente de la capa granular y de la subbase}

Se parte de la suposición de que las capas granulares no unidas acumulan deformación permanente, a partir de la deformación por corte, en la capa. Las propiedades elásticas para las capas base y subbase granular no unidas se dan en la Tabla 4. 
Tabla 4. Modulos elásticos para capas granulares

\begin{tabular}{|c|c|c|c|}
\hline \multirow[t]{2}{*}{$\begin{array}{l}\text { Material } \\
\text { Code }\end{array}$} & \multirow[t]{2}{*}{ Material Description } & \multicolumn{2}{|c|}{$\begin{array}{l}\text { Elastic Modulus } \\
\text { Support Condition }\end{array}$} \\
\hline & & Over Cemented & Over Granular \\
\hline G1 & High quality crushed stone & $250-1000(450)^{1}$ & $150-600(300)$ \\
\hline $\mathrm{G} 2$ & Crushed stone & $200-800(400)$ & $100-400(250)$ \\
\hline G3 & Crushed stone & $200-800(350)$ & $100-350(250)$ \\
\hline G4 & Natural gravel (base quality) & $100-600(300)$ & $75-350(225)$ \\
\hline G5 & Natural gravel & $50-400(250)$ & $40-300(200)$ \\
\hline G6 & Natural gravel (subbase quality) & $50-200(225)$ & $30-200(150)$ \\
\hline EG4 & Equivalent granular, G5/G6 parent material & - & $200-400(300)$ \\
\hline EG5 & Equivalent granular, G7/G8 parent material & - & $100-300(200)$ \\
\hline EG6 & Equivalent granular, G9/G10 parent material & - & $30-200(140)$ \\
\hline
\end{tabular}

Fuente: (South Afrian National Roads Agency LTD, 2013)

Las capas granulares se analizan determinando el estado de esfuerzo cortante en el medio de la capa y comparándolo con la resistencia al corte, en términos de cohesión y ángulo de fricción utilizando el modelo de Mohr-Coulomb. Este estado de resistencia al corte se conoce como factor de seguridad y se utiliza en la función de transferencia para determinar la capacidad estructural de la capa a una condición terminal de $20 \mathrm{~mm}$ de surcos en la capa.

Las constantes usadas en el modelo de daño se encuentran en fucion del nivel de confiabilidad de la carretera.

\subsubsection{Deformación permanente de subrasante}

El material de la subrasante se clasifica en cuatro categorías, en fucion de su valor de CBR, ello se puede apreciar en la Tabla 5.

Tabla 5. Clasificacion de subrasante en función de CBR

\begin{tabular}{|c|c|}
\hline Class & Subgrade CBR $(\%)$ \\
\hline SG1 & $>15$ \\
\hline SG2 & 7 to 15 \\
\hline SG3 & 3 to 7 \\
\hline SG4 & $<3^{*}$ \\
\hline
\end{tabular}

Fuente: (Department of Transport Republic of South Africa, 1996) 
En los diseños que contemplan autopistas interurbanas, colectoras interurbana, rurales y rurales con tráfico ligero, la subrasante debe tratarse hasta obtener un CBR de minimo 15, este material se denomina G7.

Para diseños de calles de acceso, se contempla un material de subrasante denominado G9 y cuyo vlor de CBR es de minimo 7.

La capa de subrasante se analiza en busca de deformación permanente en la capa, que se manifiesta como deformación o surcos anchos en la superficie del pavimento. El procedimiento usado es calcular la deformacion de compresión vertical en la parte superior de la capa. Los módulos resilientes recomendados se muestran en la Tabla 6.

Tabla 6. Modulos elásticos para capas de subrasante

\begin{tabular}{|c|c|}
\hline $\begin{array}{c}\text { Selected Layers and } \\
\text { Subgrade Material Classes }\end{array}$ & $\begin{array}{c}\text { Elastic Moduli } \\
\text { (MPa) }\end{array}$ \\
\hline G7 & 120 \\
\hline G8 & 90 \\
\hline G10 & 70 \\
\hline
\end{tabular}

Fuente: (South Afrian National Roads Agency LTD, 2013)

La funcion de transferencia (Ecuacion 4) está disponible para $10 \mathrm{~mm}$ y $20 \mathrm{~mm}$ de surcos en la capa (Tabla 7). La función de transferencia de $20 \mathrm{~mm}$ es conservadora, ya que si la subrasante o la capa seleccionada tiene $20 \mathrm{~mm}$ de surcos, entonces el surco en la superficie del pavimento es probable que sea considerablemente más alto que la profundidad de surco terminal típicamente de $20 \mathrm{~mm}$. Por lo tanto, la función de transferencia de $10 \mathrm{~mm}$ se usa más comúnmente, particularmente para carreteras de Categoría A y B.

$$
N_{P D}=10^{\left(a-10 \log \varepsilon_{v}\right)}
$$

Ecuación 4

Donde:

$N_{P D}=$ Número de ejes estándar relacionados con el nivel de deformación permanente de la subrasante 
$a=$ Constante

$\varepsilon_{v}=$ Deformación vertical por compresion en la parte superior de la subrasante

Tabla 7. Constantes usasdas en modelo de daño

\begin{tabular}{|c|c|c|}
\hline \multirow{2}{*}{ Reliability Level } & \multicolumn{2}{|c|}{$\mathbf{A}$} \\
\hline & $10 \mathrm{~mm}$ Terminal Rut Depth & 20 mm Terminal Rut Depth \\
\hline $95 \%$ (Category A) & 33.70 & 36.70 \\
\hline $90 \%$ (Category B) & 33.47 & 36.47 \\
\hline $80 \%$ (Category C) & 33.38 & 36.38 \\
\hline $50 \%$ (Category D) & 33.30 & 36.30 \\
\hline
\end{tabular}

Fuente: (South Afrian National Roads Agency LTD, 2013)

\subsection{PROGRAMA DE DISEÑO DE PAVIMENTOS DEPAV}

El programa DEPAV, fue desarrollado por el Ministerio de Transporte y el Instituto de Vías de la Universidad del Cauca y es un software que es usado para el diseño estructural de pavimentos flexibles que cuentan con número de capas entre 2 y 6 .

El programa calcula principalmente los esfuerzos y las deforaciones en las diferentes capas, causados por la acción de una rueda en la superficie de rodadura.

Para la modelación en el programa se cuenta con unos parámetros establecidos que se deben ingresar: radio de caga, presión de contacto o de inflado y distancia entre llantas. Mientras que los demás valores de entrada tales como espesor de capa, modulo de elasticidad y relación de Poisson son conocidos por el usuario. Los valores ingresados deben estar en unidades de kilogramos y centímetros.

Entre los resultados arrojados por el DEPAV son de especial importancia la deformación radial de tracción en la fibra inferior de la capa asfáltica ( $\xi r)$, la deformación vertical de compresión sobre la subrasante $(\varepsilon z)$, la deformación radial de tracción en la fibra inferior de las capas estabilizadas $(\sigma T)$, el esfuerzo vertical de compresión sobre la subrasante $(\sigma Z)$ y la deflexión en la superficie de la capa superior $(\Delta)$ (Higuera, 2007). 


\subsection{DETERIORO DEL PAVIMENTO}

Comúnmente los pavimentos se ven afectados principalmente por causas medioambientales y por efectos del tránsito.

Las condiciones medioambientales afectan la superficie y la estructura del pavimento generando agrietamiento superficial, a causa de estar bajo el sol, el viento y a la lluvia, produciendo en la superficie cambios de volumen por la variación en la temperatura y fragilidad por envejecimiento, y en la estructura disminuyendo la capacidad de soporte con la presencia de agua.

Las cargas de trafico afectan el pavimento generando ahuellamiento y grietas en su estructura según sea su magnitud y frecuencia, es decir que los vehiculos pesados tienen un efecto mas nocivo en el pavimento. Como consecuencia de las cargas repetitivas del tránsito sobre el pavimento, se genera un efecto acumulativo que con el paso del tiempo produce una deformación permanente o agrietamiento en el pavimento (Wirten, 2004).

En la Imagen 1, se puede observar como al deteriorarse un pavimento, disminuye su calidad de rodado, y ahumenta su ahuellamiiento y grietas.

\section{Imagen 1. Indicadores de deterioro de pavimentos}

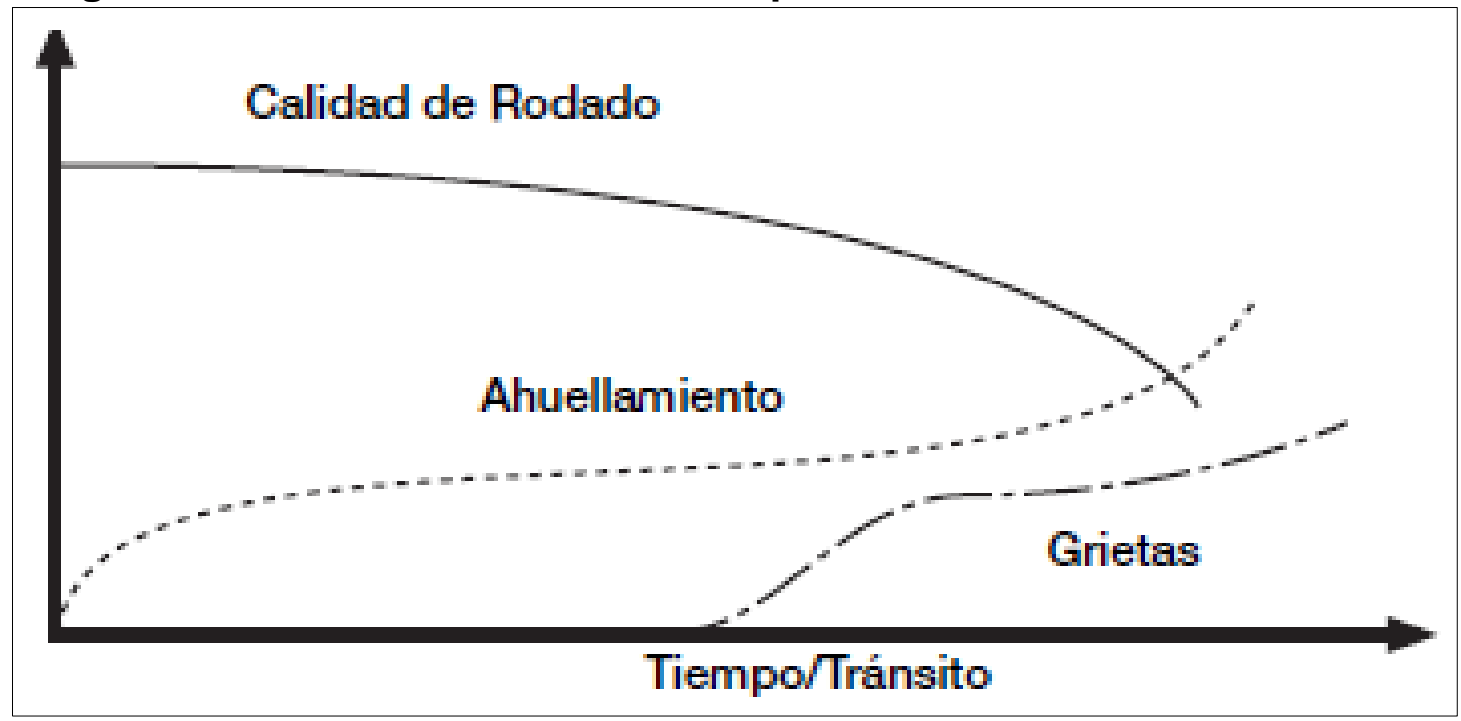

Fuente: Wirten, 2004, (pàg.21). 


\subsubsection{Mantenimiento y rehabilitación del pavimento}

Para atacar el deterioro a causa de las condiciones medioambientales, a vías de tráfico liviano se les puede realizar mantenimiento con el fin de mantener la superficie en una condición de impermeabilidad, y tomar medidas de drenaje efectivas. El mantenimiento incluye acciones superficiales como sellar grietas a medida que aparecen y aplicar emulsiones para tratar el envejecimiento. Para vías de tráfico pesado el mantenimiento se debe realizar con un recapado asfaltico convencional.

Para atacar la deformación y grietas de fatiga a causa de las condiciones del transito, se debe realizar una rehabilitación ya que con un mantenimiendo no se pueden tratar de forma efectiva (Wirten, 2004).

Generalmente el pavimento se deteriora lentamente, pero la realizacion oportuna de acciones de mantenimiento y rehabilitación garantiza una buena calidad del rodado por mayor tiempo, como se observa en la Imagen 2.

Imagen 2. Calidad del rodado en función del mantenimiento y rehabilitacón oportuna

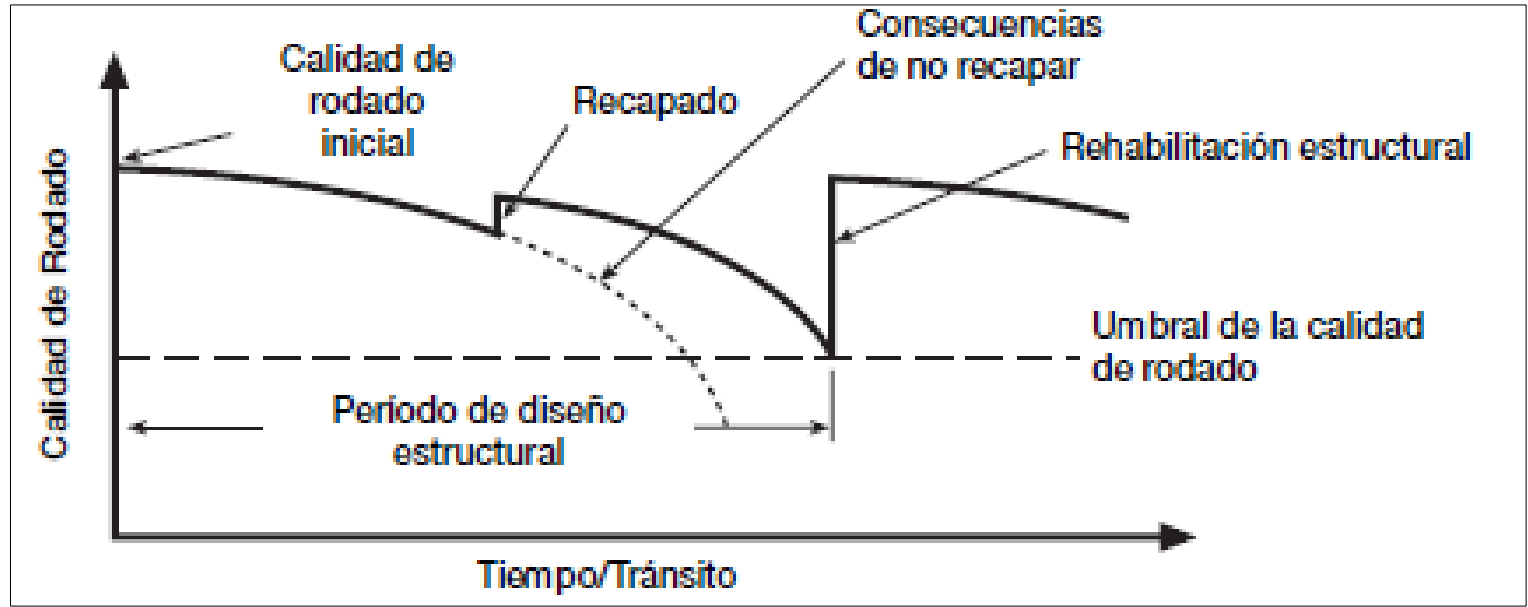

Fuente: Wirten, 2004, (pàg.24). 


\subsubsection{Opciones de rehabilitación de un pavimento}

Rehabilitación superficial: Se realiza entre los 5 a 10 centrimetros superficiales del pavimento y los métodos más usados son: El recapado consiste en la construcción de una capa de entre 4 y 5 centimetros de mezcla asfáltica en caliente sobre la superficie existente. $Y$ el fresado-reemplzado que consiste en remover la capa deteriorada por agrietamento del asfalto y luego reemplazarla.

Rehabilitación estructural: Corresponde a una solución a largo plazo que apunta a conseguir el máximo beneficio a partir del valor residual del pavimento existente. La opciones mas utilizadas son: Reconstruccion total, construcción de capas adicionales y reciclado profundo (Wirten, 2004).

\subsection{RECICLADO DE PAVIMENTOS}

El reciclaje de un pavimento asfaltico se basa en la reutilización de carpetas asfálticas de las mismas o de otras estructuras que una vez cumplen su tiempo de uso son demolidas mediante un proceso denominado fresado. El fresado consiste en el molido en frio controlado automáticamente, de la superficie del pavimento deteriorado con una maquina llamada fresadora (Montejo, 2006), su ejecución es detallada en la sección 540-11 de las especificaciones IDU donde se señalan algunos aspectos que se deben tener en cuenta para su realizacion como (Instituto de Desarollo Urbano de Bogota D.C., 2011b) :

- La superficie de pavimento a la que le realizara el fresado ser barrida y soplada previamente.

- No se deben adicionar solventes ni productos ablandadores que afecten las propiedades del asfalto existente.

- El fresado debe ser suspendido si se presenta lluvia.

Como producto del fresado se obtiene el pavimento asfaltico reciclado (RAP) que es usado para la construcción de nuevas vías al ser mezclarlo generalmente con emulsiones asfálticas, espuma de asfalto o cemento, mejorando algunas de las características de resistencia de la nueva estructura vial. 
Entre las limitaciones del proceso de fresado se encuentran la granulometría y el exceso de ligante presente en la capa reciclada, los cuales pueden exigir una corrección con aporte de material granular virgin (CEDEX, 2011).

El reciclado de pavimento puede realizarse en planta o en sitio y puede hacerse en Frio o en caliente según sean las características y presupuesto del proyecto. El reciclado en sitio tiene un menor costo, especialmente el reciclado superficial en caliente que interviene poca profundidad y el cual es poco aplicado en el país especialmente por la escases de equipos para su ejecución (Instituto Nacional de Vías de Colombia, 2008).

En cuanto al reciclado en sitio en frío empleando ligantes bituminos debe ser aplicado bajo el Articulo 461-13 de las especificaciones INVIAS, donde se encuentra descrito el procedimiento para el cual es utilizada una maquina recicladora que en una sola pasada ejecuta las operaciones de disgregación, adición de fluidos y mezcla homogénea. Así mismo se especifica el uso de ligantes como la emulsión asfáltica de rompimiento lento de tipo CRL-1 y el cemento asfaltico espumado de penetración 80-100, a fin de producir un mezcla con características comparables a una base estabilizada con emulsión asfáltica elaborada con agregados y ligante asfaltico nuevos (Instituto Nacional de Vías de Colombia, 2013).

Por otro lado el reciclado en planta y en caliente que debe realizarse bajo los parámetros del Artículo 462-13 de las especificaciones INVIAS, cuenta con mayor aplicación en el país y consiste en triturar en planta y clasificar por tamaño el fresado traído para luego ser usado en una nueva mezcla en caliente que cumpla con los mismos requisitos de calidad que un concreto asfaltico convencional (Instituto Nacional de Vías de Colombia, 2008). Sin embargo para el reciclaje en planta en frio no existe un lineamiento normativo definido en el país.

\subsubsection{Reciclado de pavimentos con cemento}

Con el uso de cemento como aglomerante en el reciclado en frio se aumenta la capacidad de carga de las calzadas, mientras que con la emulsión asfáltica se aumenta su flexibilidad y se reduce la formación de fisuras (Wirtgen gmbH, 2016). Por lo anterior en ocasiones se realiza un reciclado mixto empleado los dos aglomerantes, con lo cual se logra aumentar la resistencia en presencia de agua sin sacrificar significativamente la resistencia a la fatiga (Instituto Nacional de Vías de Colombia, 2008).

La resistencia que se adquiere con la estabilizacion con cemento, depende de la cantidad de cemento y del tipo de material que se esta tratando, y agregar 
demasiado cemento puede ser prejudicial para el desempeño de la capa debido a que despues de aumentar la resistencia hace que el material sea mas fragil y disminuya la flexibilidad, llevando a una proliferacion de las griestas ante cargas repetitivas de trafico reduciendo el desempeño structural, por ello es importante determinar la correcta tasa de aplicacion (Wirtgen $\mathrm{GmbH}$, 2004).

En la ciudad de Bogotá el reciclado en frio en sitio con cemento, debe realizarse bajo los requisitos de la sección 454-11 de las especificaciones IDU, usando una maquina recicladora encargada de disgregar el pavimento existente y mezclar adecuadamente los ingredientes, para que luego se pueda realizar la extensión, nivelación y homogenización de la mezcla con una motoniveladora, y finalmente la compactación (Instituto de Desarollo Urbano de Bogota D.C., 2011a).

\subsection{RESILIENCIA EN PAVIMENTOS}

Una estructura vial a causa del paso de vehículo se ve sometida a ciclos de carga y descarga que producen deformaciones recuperables (resilientes) y permanentes (Rondón \& Lizcano, 2007), y por ello es de gran importancia tener en cuenta estos aspectos a la hora de diseñar un pavimento.

Bajo carga móvil y repetida, la deformación permanente (plástica) se va acumulando y puede llegar a alcanzar valores inadmisible, proceso que va acompañado de una "densificación" de los materiales, de manera que el pavimento fallado puede ser más resistente que el original (Instituo Mexicano del Transporte, 2001).

En la Imagen 3, se muestra como la deformación permanente se va acumulando y como en los ciclos intermedios la deformación permanente para cada ciclo disminuye, hasta que prácticamente desaparece en los ciclos finales (Instituo Mexicano del Transporte, 2001). 


\section{Imagen 3. Deformacion acumulada despues de $\mathbf{N}$ ciclos.}

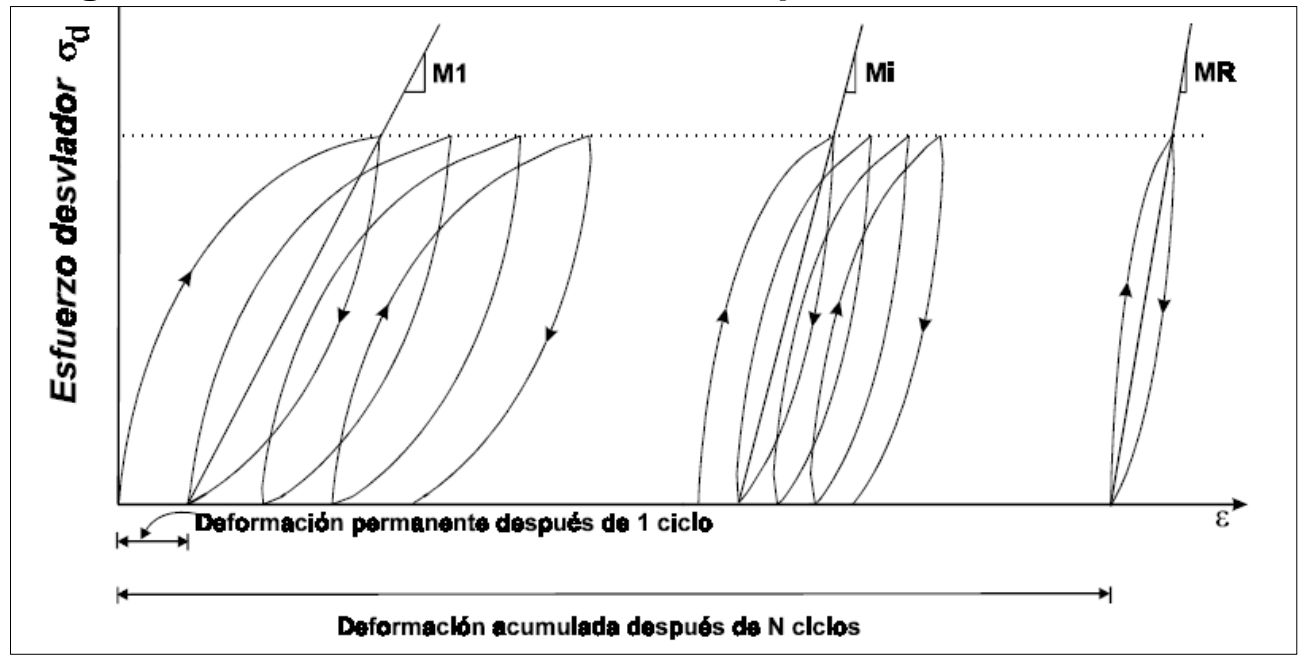

Fuente: Instituto Mexicano del Transporte (pàg.9).

La deformacion elastica es de mayor relevancia en las carpetas asfalticas o en capas estabilizadas colocadas en la parte superior de la seccion, donde se puede generar una falla de agrietamiento por fatiga.

El módulo resiliente es un valor que indica la capacidad de cualquier material para almacenar o absorber energía sin deformación permanente.y se utiliza para el análisis multicapa permitiendo predecir esfuerzos resilientes (recuperables), deformaciones y deflexiones dentro de un pavimento flexible. Es igual al esfuerzo axial pico repetido dividido entre la deformación axial recuperable que se da en un especimen (Jiménez, 2009) y su valor depende principalmente de la presión de confinamiento y que se relaciona directamente con la suma de los esfuerzos principales (Rondón \& Lizcano, 2007).

El modulo resiliente es considerado como propiedad fundamental en la caracterizacion de los materiales que forman la secccion de una carretera, en el metodo de diseño de pavimentos de la AASHTO.

Tradicionalmente para su cálculo se han usado modelos empíricos basados en el CBR que no tienen en cuenta el estado de esfuerzos, hasta que fue posible simular dichos esfuerzos por medio de equipos de laboratorio (Jiménez, 2009). Actualmente con base en la normatividad nacional, el módulo resiliente puede obtenerse mediante dos ensayos del INVIAS: En primer lugar el ensayo INV E-15613 en el cual se aplica una carga axial cíclica en una cámara de presión triaxial, y en segundo lugar el ensayo de tensión indirecta con carga repetida (INV E-749-13). 


\section{ESTADO DEL ARTE}

La infraestructura vial de un país interviene directamente en su desarrollo, tal que contar con las vías necesarias y que brinden un servicio adecuado y eficiente a sus usuarios, permite mejorar la calidad de vida de la sociedad y mejorar sus procesos productivos.

En la actualidad no es suficiente tan solo con realizar cada vez más vías, sino que se deben diseñar y construir teniendo en cuenta que ello genere el menor impacto ambiental posible. Es por ello que en la última década en Colombia ha aumentado el interés por los temas de aprovechamiento de desechos de construcción como un aporte a la disminución de su impacto, y desde el punto de vista económico como ahorro en los costos de materiales de construcción.

\subsection{PAVIMENTO RECICLADO}

En esta investigación se trabaja con una base con un $50 \%$ de residuo de construcción denominado "RAP" correspondiente al pavimento asfáltico reciclado obtenido a través de un proceso de disgregado de una capa asfáltica existente (fresado), y que puede usarse en las capas de una nueva vía al ser estabilizado con ligantes hidráulicos o emulsiones asfálticas, siendo estas últimas las más utilizadas y estudiadas. Dentro y fuera del país se han adelantado estudios correspondientes al comportamiento mecánico de estas mezclas, variando algunas de sus características con el fin de identificar posibles inconvenientes, mejoras, usos óptimos y parámetros a tener en cuenta en el momento de diseñar y construir nuevas estructuras viales con este material reciclado.

Entre las investigaciones académicas adelantadas en Colombia respecto al uso del RAP, se ha evaluado la respuesta mecánica de este material al ser estabilizado con emulsión asfáltica catiónica de rompimiento lento en diferentes dosificaciones, por ejemplo en el trabajo titulado: "influencia de la granulometría y la dosificación en el fresado estabilizado con emulsión asfáltica", se analizó la respuesta mecánica de la mezcla a través de ensayos de densidad, estabilidad-flujo, inmersión compresión y módulos dinámicos, estableciendo que el material estudiado en este caso solo era apto para estructuras de pavimento de trafico bajo o como material granular de relleno (Burbano \& Zuluaga, 2011).

Otros estudios académicos nacionales han centrado su interés en el efecto del tiempo de curado de mezclas en frio de RAP y emulsión asfáltica para obtener un diseño de mezcla óptimo con alta resistencia a la tracción indirecta. Por ejemplo en 
el trabajo titulado: "Evaluación de mezclas asfálticas en frío con pavimento reciclado utilizando diferentes dosificaciones y tiempos de curado", tras varios ensayos modificando la dosificación de emulsión y el tiempo de curado se determinó que el tiempo de curado es fundamental en la resistencia del material, evidenciando que con el aumento del tiempo, los esfuerzos mínimo y máximo crecieron en $31 \%$ y $48 \%$ respectivamente (Cardoso, 2016).

Algunos trabajos académicos en el país, además de revisar el comportamiento mecánico de las mezclas de RAP con emulsión, han analizado los efectos de la adición de diferentes porcentajes de cemento en esta mezcla. Al respecto, el documento titulado: "Evaluación del comportamiento mecánico de mezclas asfálticas utilizando pavimento reciclado, ligantes hidráulicos y emulsiones asfálticas", destaca que fueron evaluados parámetros de estabilidad-flujo, tracción indirecta, inmersión-compresión, ahuellamiento y módulo dinámico, y estudiando sus resultados se encontró que la adición de cemento en la mezcla reciclada favorece su durabilidad en función del tráfico, haciéndola menos susceptible al efecto del agua y por consiguiente más durable (Hernández, 2014).

En algunas investigaciones académicas colombianas se ha determinado que los residuos de construcción pueden ser utilizados en estructuras de pavimentos como base o sub-base, y se ha estudiado con más profundidad la variación del módulo resiliente con la modificación de diferentes parámetros como el tiempo de cura. Muestra de ello se encuentra el documento titulado: "Utilización de residuos de construcción y demolición (RCD) ligados con materiales cementantes en pavimentos", en el cual se encontró que al aumentar el contenido de cemento en las muestras mejoró la resistencia a la penetración del material, aumentando así el CBR, la resistencia a la compresión incofinada y el módulo resiliente. Por otro lado se pudo establecer que el tiempo de cura es un aspecto relevante en el estudio de las cargas cíclicas que soporta el material, encontrando un aumento aproximadamente del $60 \%$ en el módulo resiliente de las muestras a los 28 días comparado con el valor obtenido a los 7 días (Barrera \& Olmedo, 2015).

También a nivel internacional se han producido variedad de documentos académicos que reflejan el interés por el tema del pavimento reciclado. En consecuencia el trabajo titulado: "El estudio del comportamiento de los firmes reciclados in situ con cemento" de la Universidad de Burgos en España, determino que debido a la variabilidad de las características del RAP que se puede conseguir, la adición de cemento a la mezcla debe ser mayor al $3 \%$ con el fin de asegurar la resistencia del material en el tiempo y además se recomienda ser generoso en la dosificación del cemento con el fin de evitar una posterior disminución en la resistencia de la mezcla a causa de un incremento de finos. Por otro lado se pudo identificar que al aumentar la densidad del material, aumenta su resistencia a la compresión y su resistencia a la tracción indirecta (Minguela, 2011). 


\subsection{RELACION MODULO RESILIENTE - CAPA CEMENTADA - RAP}

En cuanto al estudio del módulo resiliente, su cálculo y las variables que lo afectan se encuentran disponibles algunos documentos aplicables como el trabajo académico: "Relación entre el módulo resiliente hallado por retrocálculo y el encontrado en ensayos de laboratorio", en el cual se encontró que al aumentar el contenido de humedad en el interior de las muestras se presenta una disminución en el módulo resiliente. Así mismo se evidenció un aumento del módulo en los materiales (base y sub-base) que contenían un mayor porcentaje de finos, y un aumento directo con el esfuerzo de confinamiento, independientemente de la humedad de compactación de las muestras (Leal, 2010).

Respecto a la variación del módulo resiliente en las mezclas cementadas con pavimento reciclado existen diferentes publicaciones científicas, entre las cuales se encuentra el artículo: Resilient Moduli Response of Moderately Cement-Treated Reclaimed Asphalt Pavement Aggregates, en el cual se describe la evaluación de las características resilientes del RAP estabilizado con cemento al variar las dosis de cemento, se analizaron las tensiones de confinamiento y de desviación, y se encontró que los valores de módulo resiliente aumentaron aproximadamente en un $33 \%$ por la adición de un $2 \%$ de cemento, y en un $50 \%$ por la adición de un $4 \%$ de cemento. Así mismo se obtuvieron valores de coeficiente estructural entre 0,16 y 0,22 , sugiriendo que el material aumentó su soporte estructural a causa del tratamiento realizado (Puppala, Hoyos, \& Potturi, 2011).

El porcentaje de contenido de cemento en la mezcla es fundamental en su comportamiento mecánico, como se evidencia en el estudio descrito en el artículo: "Influence of high content of reclaimed asphalt on the mechanical properties of cement-treated base under critical environmental conditions", en el cual se detalla el estudio experimental de las propiedades mecánicas bajo distintas condiciones ambientales, de mezclas de bases tratadas con cemento y altos porcentajes de RAP. En este estudio se encontró que la adición de RAP aumenta óptimamente el contenido de humedad, y reduce la densidad seca máxima, y que con el aumento del contenido de cemento se mejora significativamente la resistencia del material, tal que con una adición del $5 \%$ resulto tres veces mayor que la obtenida con una adición del 3\% (Adresi, khishdari, Ahmadi, \& Rooholamini, 2017).

Como resultado de diversos ensayos de laboratorio se ha encontrado un aumento en el peso unitario seco y en el módulo dinámico al aumentar el cemento en la mezcla, tema abordado como planteado por Consoli, Pasche, Specht y Tanski (2017) en el artículo: "Key parameters controlling dynamic modulus of crushed reclaimed asphalt paving-powdered rock-Portland cement blends", en el cual 
también se determinó que el módulo dinámico de la mezcla de RAP con polvo de roca con cemento, se ve afectado por la cantidad de cemento, la porosidad, la frecuencia de carga y la temperatura del ensayo.

Recientemente tomó interés el estudio del efecto del tiempo de curado y del esfuerzo de compactación sobre el valor del módulo resiliente al variar el contenido de cemento y de RAP en la mezcla, como presentado por Fedrigo, Peres, Castañeda, Kleinert y Pereira (2018) en "A study on the resilient modulus of cementtreated mixtures of RAP and aggregates using indirect tensile, triaxial and flexural tests", en el cual se pudo establecer que al aumentar el contenido de cemento, el tiempo de curado y el esfuerzo de compactación, aumenta la fuerza y la rigidez de la mezcla, mientras que estas mismas características disminuyen al aumentar el contenido de RAP.

Dentro de las últimas investigaciones al respecto se encuentra el estudio de mezclas cementadas con RAP y con agregados vírgenes, las cuales han estado sometidas a determinado periodo de servicio. Los detalles de este trabajo se pueden revisar en el artículo: "Evaluation of "long-term behavior under traffic" of cement treated mixture with RAP", para el cual se realizaron pruebas estáticas y cíclicas al material mixto, comparando sus resultados con los obtenidos para una mezcla con solo agregado virgen, con lo cual se pudo determinar que se puede remplazar una parte del agregado virgen por RAP, sin obtener una alteración significativa en su comportamiento mecánico (Romeo, Orazi M., Orazi U., Accardo, Noto \& Tebaldi, 2019).

En cuanto a documentación técnica correspondiente al RAP, actualmente a nivel Distrital en las especificaciones técnicas generales de materiales y construcción para proyectos de infraestructura vial y de espacio público para Bogotá, se halla la sección 454-11 titulada reciclaje de pavimento asfáltico en sitio con cemento Portland, donde se describe el procedimiento para su realización en la ciudad de Bogotá, se recomienda una granulometría y se especifican los valores aptos para algunos ensayos de laboratorio del material.

\subsection{DISEÑO DE PAVIMENTOS ASFALTICOS METOLOGÍA AASHTO Y SUDAFRICANA}

Entre las investigaciones académicas internacionales respecto a las metodologías de diseño en cuestión, se encuentra el documento: "Diseño estructural de un pavimento básico reciclado y mejorado con cemento portland para diferentes dosificaciones en el proyecto de conservación vial de Huancavelica", en la cual se diseño bajo metodología AASHTO y se logró determinar que agregar un agente 
estabilizador como el cemento portland, asi fuera en pequeños porcentajes ( $1 \%$ al $2 \%$ ) permite reducir los espesores necesarios de capa, lo que se traduce también en un ahorrro de costos (Descalzi et al., 2017).

En el trabajo de grado: "Análisis comparativo de métodos de diseño de pavimentos flexibles" se establecio que el método AASHTO es la metodología que requiere mayor numero de consideraciones de diseño en comparación con el modelo Sudafricano, y se determinó que en las dos metodologias al diseñar una estructura de pavimento contemplando una mejor calidad de la subrasante, los espesores de las capas tienden a disminuir (Rodriguez, 2013).

El estudio académico denominado: "Efectos de la alta compactación de la capa de base en pavimentos flexibles", cuantifica en laboratorio la influencia en la capacidad de soporte de un agregado triturado para capa de base, compactado a altas densidades y establece una semejanza con el modelo de diseño Sudafricano por la aplicación de altos grados de densidad a la capa de base permitiendo espesores de capas mas delgadas (Morales Cárdenas, Chávez Arévalo, \& López Poveda, 2009). 


\section{PREGUNTA DE INVESTIGACIÓN}

¿Cual es la influencia del coeficiente estructural de una base reciclada con cemento respecto a la deformación permanente de la subrasante evaluando el modelo de daño del método Sudafricano? 


\section{ALCANCES Y LIMITACIONES}

Con la revisión bibliografía realizada, se evidenció que existe un vacio en el tema específico de la influencia del coeficiente estructural de una base reciclada con cemento sobre la deformación permanente en la subrasante. Por un lado se ha estudiado un poco más el tema de estabilización con emulsiones asfálticas y es por ello que se cuenta con mayor información sobre el comportamiento mecánico de este material, generando su preferencia en el diseño y construcción de nuevas estructuras viales.

Teniendo en cuenta lo expuesto anteriormente, con esta investigación se pretende ampliar la información de consulta existente en el país respecto al tema de como influye el uso de una base reciclada con cemento en el diseño de una estructura vial, respecto a la deformación permanente en la subrasante, especificacamente en función de la variacion del coeficiente estructural de la capa BRC.

Una limitante de la investigación corresponde a que no se estudiará el comportamiento de la totalidad de las capas del pavimento. Es evidente que ello brindaría un panomara amplio y más preciso de la repuesta probable de las estructuras diseñadas con una base RAP-Cemento, pero la investigación esta dirigida al análisis de la deformación permanente de la subrasante en funcion del uso de dos diferentes coeficientes estructurales para la capa reciclada, cuyos valores son recomendados por el INVIAS y se basan en el "Manual de reciclado en frío" de la Wirten.

En la presente investigación no se contempla la realización de ensayos de laboratorio de ningún tipo debido a que no se cuenta con los recursos necesarios y por ende no hacen parte del objetivo de estudio. Se realizaran unicamente cálculos para el diseño AASHTO, modelaciones en el software DEPAV, y aplicación de funciones de transferencia del modelo Sudafricano a partir de la informacion recopilada durante la investigación.

Una limitación importante en la investigación propuesta corresponde al desconocimiento de la totalidad de caracteristicas del RAP de Bogota que será usado en la base cementada, debido a que no es posible concocer donde estaba puesto antes de ser recuperado, cual fue su tiempo de uso, el espesor de la capa que conformaba, el contenido de asfalto del material o que tipo de afectaciones presentaba a causa del trafico soportado.

En consecuencia, debido a la heterogeneidad característica del RAP los resultados de este estudio pueden ser usados como un acercamiento el comportamiento probable de la deformación permanente en la subrasante pero no deben ser 
generalizados puesto que también existe desconocimiento en cuanto a las caracteristicas reales de la subrasante de la ciudad de Bogota resultando variable el comportamiento mecanico de material durante su vida útil, según sea el lugar de la ciudad donde sea puesto. 


\section{METODOLOGÍA}

En la imagen 4 se muestra el diagrama que representa la metodología a adelantar para la realización de esta investigación.

\section{Imagen 4. Diagrama metodología}

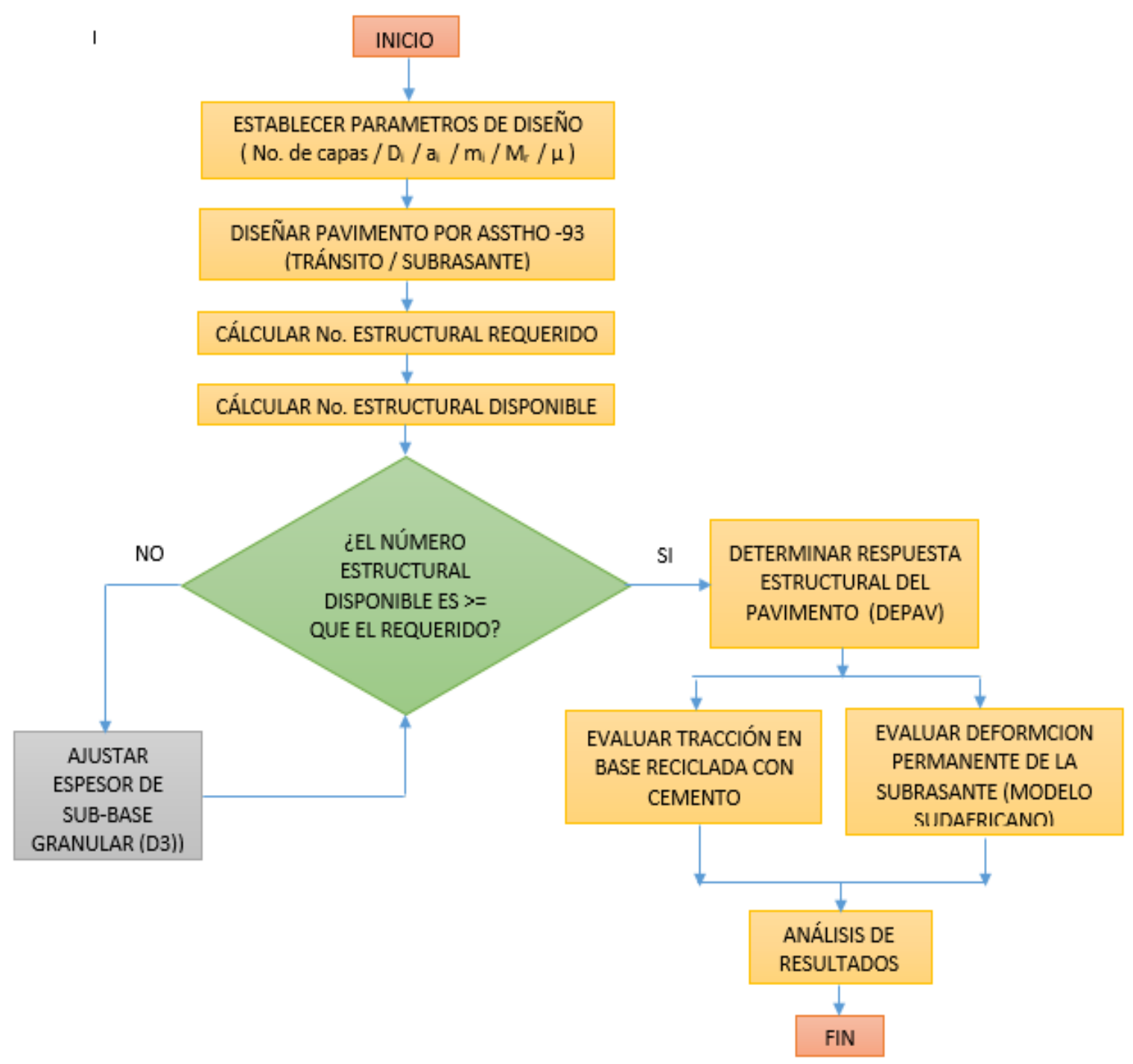

Fuente: Autor. 
Se inició con el diseño de una estructura típica de pavimento flexible, basada en la alternativa estructural número cinco del Manual de diseño de pavimentos asfalticos de INVIAS, compuesta por tres capas: carpeta asfáltica, base granular y sub-base granular.

El diseño se realizó bajo la metodología AASHTO-93 para doce diferentes combinaciones entre calidad de la subrasante y nivel de tránsito, obteniendo los espesores adecuados de sub-base granular para cumplir con los números estructurales (SN) determinados a partir de la ecuación básica de diseño.

A continuación se realizo la modelacion en el software DEPAV para las diferentes combinaciónes realizadas, encontrando los valores de esfuerzos y deformaciones en cada capa de la estructura.

Finalmente con los valores de deformación de compresión en la subrasante (Épsilon Z) obtenidos en el DEPAV se evaluó la función de transferencia del manual de Ingeniería de pavimentos Sudafricanos para analizar la deformación permanente de la subrasante en las diferentes simulaciones realizadas.

\subsection{MATERIALES CONTEMPLADOS PARA DISEÑO DEL PAVIMENTO}

\subsubsection{Carpeta asfáltica}

La carpeta asfáltica (CA) corresponde a una mezcla densa en caliente tipo 2 (MDC2), con un coeficiente estructural $\left(a_{1}\right)$ típico igual a 0,41 (Instituto Nacional de Vías de Colombia, 2008). Partiendo de dicho coeficiente se despejó el valor de módulo resiliente $\left(M R_{1}\right)$ en la fórmula correspondiente de la metodología AASHTO, relacionada a continuación, y se obtuvo un valor de $M R_{1}=381410,09$ PSI (26 $815,78 \mathrm{~kg} / \mathrm{cm} 2)$.

$$
a_{1}=0,184 * \ln \left(M R_{1}\right)-1,9547 \quad \text { Ecuación } 5
$$

Así mismo para esta capa se asumió un espesor $\left(D_{1}\right)$ de 3 pulgadas $(7,62 \mathrm{~cm})$ atendiendo lo recomendado para estructuras con un número mayor de 500000 ejes equivalentes, para lo cual se requiere un espesor mayor de $7,5 \mathrm{~cm}$ (Instituto Nacional de Vías de Colombia, 2007).

En cuanto el coeficiente de Poisson para la carpeta asfáltica se tomó el valor recomendado como típico de 0,35 (Meza, 2008). 


\subsubsection{Base reciclada con cemento}

Para la capa intermedia se trabajó con una base reciclada con cemento (BRC), compuesta por un $50 \%$ de base granular normalizada, $50 \%$ de pavimento asfaltico reciclado (RAP) y cemento (6\%), la cual se dejó con un espesor $\left(D_{2}\right)$ de 6 pulgadas $(15,24 \mathrm{~cm})$ cumpliendo con la altura mínima de $15 \mathrm{~cm}$ necesaria (Instituto Nacional de Vías de Colombia, 2008).

Teniendo en cuenta que el módulo para un material estabilizado con cemento se encuentra entre $5000 \mathrm{MPa}$ y $10000 \mathrm{MPa}$ (Instituto Nacional de Vías de Colombia, 2008), en este caso se tomó para diseño un módulo resiliente $\mathrm{Mr}=5000 \mathrm{MPa}$ (50 $985,80 \mathrm{~kg} / \mathrm{cm} 2)$.

En cuanto al coeficiente estructural $\left(a_{2}\right)$ se usaron los dos valores típicos 0,12 y 0,17 , correspondiendo el primero a una capa reciclada con una resistencia a compresión inconfinada menor a $1 \mathrm{MPa}$, y el segundo a una capa con una resistencia a compresión inconfinada entre 1 y $3 \mathrm{MPa}$ (Instituto Nacional de Vías de Colombia, 2008).

Respecto a la relación de Poisson se tomó el valor de 0,25 generalmente el más usado (Instituto Nacional de Vías de Colombia, 2008).

\subsubsection{Sub-base granular}

A la capa de sub-base granular (SBG) se le asignó un valor típico de coeficiente estructural $\left(a_{3}\right)$ de 0,12, (Instituto Nacional de Vías de Colombia, 2007), y a partir de éste valor se despejo el módulo resiliente en la fórmula de la metodología AASHTO relacionada a continuación y con la cual se obtuvo un valor de $\mathrm{Mr}=16$ 775,27 PSI (1 179,42kg/cm2).

$$
a_{2}=0,227 * \log \left(M R_{3}\right)-0,839 \quad \text { Ecuación } 6
$$

Para esta capa se asumió el coeficiente de Poisson recomendado como típico de 0,40 (Meza, 2008) y el espesor inicial $\left(D_{3}\right)$ se tomó como 6 pulgadas $(15,24 \mathrm{~cm})$ cumpliendo con el valor mínimo correspondiente a $15 \mathrm{~cm}$ (Instituto Nacional de Vías de Colombia, 2007). El espesor final $\left(D_{3} *\right)$ de la capa varía según la combinación usada entre categoría de subrasante y nivel de tránsito, y obedece al valor necesario para alcanzar el número total estructural $(\mathrm{SN})$ requerido, calculado a través de la metodología AASHTO-93. 


\subsection{DISEÑO PAVIMENTO (METODOLOGÍA AASHTO-93)}

\subsubsection{Variables de diseño}

Subrasante: Según su comportamiento la subrasante se clasifica en cuatro categorías (Tabla 8), desde S1 (malo) a S4 (muy bueno).

Tabla 8. Categorías de subrasante

\begin{tabular}{|c|c|c|}
\hline CATEGORIA & CBR $(\%)$ & $\begin{array}{c}\text { COMPORTAMIENTO } \\
\text { COMO SUBRASANTE }\end{array}$ \\
\hline $\mathrm{S} 1$ & $\mathrm{CBR} \leq 3$ & Malo \\
\hline $\mathrm{S} 2$ & $3<\mathrm{CBR} \leq 5$ & Regular \\
\hline $\mathrm{S} 3$ & $5<\mathrm{CBR} \leq 10$ & Bueno \\
\hline $\mathrm{S} 4$ & $\mathrm{CBR}>10$ & Muy Bueno \\
\hline
\end{tabular}

Fuente: Instituto Nacional de Vías de Colombia, 2007

A cada categoría de subrasante se le calculo el módulo resiliente mediante la ecuación:

$$
M R=1500 * C B R \quad \text { Ecuación } 7
$$

Así a la categoría S1 se le asignó un CBR $=3 \%$ para un MR $=4500$ PSI $(316,38$ $\mathrm{kg} / \mathrm{cm} 2)$, a la categoría S2 un CBR $=5 \%$ para un MR $=7500 \mathrm{PSI}(527,30 \mathrm{~kg} / \mathrm{cm} 2)$, a la categoría S3 un $\mathrm{CBR}=10 \%$ para un MR $=15000 \mathrm{PSI}(1054,60 \mathrm{~kg} / \mathrm{cm} 2)$, y a la categoría S4 un CBR= 20\% para un MR $=30000 \mathrm{PSI}(2109,21 \mathrm{~kg} / \mathrm{cm} 2)$.

Transito: Respecto a la variable de diseño que considera el número de ejes equivalentes de $80 \mathrm{KN}$ en el carril de diseño, se evaluaron tres niveles de tránsito (Instituto Nacional de Vías de Colombia, 2015) para cada una de las cuatro categorías de subrasante.

En cuanto al nivel de transito 1 (NT1) se contemplo su valor límite equivalente a 0,5 millones de ejes, respecto al nivel de transito 2 (NT2) que se encuentra entre 0,5 y 
5 millones de ejes, se tomó el valor de 5 millones de ejes, y para el nivel de transito 3 (NT3) con más de 5 millones de ejes se tomó el valor de 10 millones de ejes.

Índice de serviciabilidad: La pérdida de serviciabilidad esperada para el diseño $(\triangle \mathrm{PSI})$, correspondiente a la diferencia entre el índice de servicio inicial y el índice de servicio final del pavimento se asumió con un valor de 2.0.

Condiciones ambientales y de drenaje: El coeficiente de drenaje $\left(m_{i}\right)$ se tomó con un valor de 1 , asumiendo un drenaje bueno con exposición a un nivel de humedad de un $25 \%$ del tiempo en el año.

Nivel de confiabilidad: Para el diseño se contempló una vía colectora urbana con un nivel de confiabilidad (R) del $90 \%$, es decir con un $90 \%$ de probabilidad de que la estructura falle después de soportar el número de ejes equivalentes de diseño y un $10 \%$ de probabilidad de que falle antes. Así mismo para la confiabilidad del $90 \%$ corresponde un valor de coeficiente $\mathrm{Zr}$ de -1,282.

Desviación estándar: Teniendo en cuenta que el diseño corresponde a un pavimento flexible y a una estructura nueva, se tomó el valor de 0,45 como desviación estándar $\left(S_{0}\right)$ para el diseño.

\subsubsection{Caculo numero estructural requerido para la estructura}

Se aplicó la ecuación básica de diseño (Ecuacion 1) de un pavimento flexible bajo la metodología AASHTO para el cálculo del número estructural requerido $\left(S N_{0}\right)$, en función de las categorías de subrasante y de tránsito consideradas en cada caso. Como aclaración a ecuación se repite a continuación:

$$
\log N_{80 k N}=Z r \times S o+9.36 \log (S N+1)-0.20+\left[\frac{\log \left(\frac{\Delta P S I}{4.2-1.5}\right)}{0.40+\frac{1094}{(S N+1)^{5.19}}}\right]+2.32 \log M_{r}-8.07
$$


El valor de $N_{80 \mathrm{kN}}$ corresponde al número de ejes equivalentes de $80 \mathrm{KN}$ en el carril de diseño (500 000, 5000000 y 10000 000) según el caso, el valor de $M_{r}$ corresponde al módulo resiliente de la subrasante según su categoría (S1, S2, S3 Y S4), y las demás variables que fueron estimadas previamente se presentan resumidas en la Tabla 9.

Tabla 9. Consideraciones fijas para cálculo de (SNO)

\begin{tabular}{|l|c|c|}
\hline \multirow{2}{*}{ Confiabilidad } & $\mathrm{R}$ & $90 \%$ \\
\cline { 2 - 3 } & $\mathrm{Zr}$ & $-1,282$ \\
\hline Desviación estandar del diseño & So & 0,45 \\
\hline Indice de Serviciabilidad (in) & $\Delta \mathrm{PSI}$ & 2 \\
\hline
\end{tabular}

Fuente: Autor

\subsubsection{Caculo numero estructural disponible por la estructura}

Se procedió a calcular los números estructurales de cada una de las tres capas del pavimento diseñado y luego se sumaron para obtener el número estructural total disponible, usando la Ecuacion 2, mostrada nuevamente a continuación:

$$
S N=S N 1+S N 2+S N 3
$$

Donde:

$S N 1=a_{1} * D_{1}$

$S N 2=a_{2} * D_{2} * m_{2}$

$S N 3=a_{3} * D_{3} * m_{3}$

Para la capa 2 (Base Reciclada con Cemento) se usaron dos coeficientes estructurales $\left(a_{2} y a_{2}{ }^{\prime}\right)$, por tanto el segundo numero estructural para dicha capa, se determinó como se indica a continuación:

$$
S N 2^{\prime}=a_{2}^{\prime} * D_{2} * m_{2} \quad \text { Ecuación } 8
$$


Teniendo en cuenta lo anterior, el segundo número estructural total disponible se calculó como sigue:

$$
S N^{\prime}=S N 1+S N 2^{\prime}+S N 3
$$

Ecuación 9

\subsubsection{Calculo espesor ajustado de sub-base granular $\left(D_{3} *\right)$}

En los casos en que los números estructurales disponibles calculados con una altura de SBG de 6 pulgadas resultaron menores que los requeridos (Tabla 3) se procedió a aumentar el espesor de la sub-base granular con la siguiente ecuación, tal que con esta nueva altura de capa ajustada $\left(D_{3} *\right)$ se consiguiera que los dos números estructurales, requerido y disponible, fueran iguales, satisfaciendo así el diseño bajo la metodología AASHTO.

$$
D_{3} *=\frac{S N_{0}-S N_{1}-S N_{2}}{a_{3} * m_{3}} \quad \text { Ecuación } 10
$$

\subsection{MODELACIÓN EN EL SOFTWARE DEPAV}

Con los valores de módulo resiliente, relación de Poisson y espesores de capas estimados previamente, se realizó una modelación en el software DEPAV de la Universidad del Cauca, con el fin establecer el comportamiento de las estructuras diseñadas anteriormente bajo la metodología AASHTO, determinando los esfuerzos y las deformaciones generados en cada capa del pavimento, con la simulación de la acción de una llanta actuando en la superficie de rodadura de la vía.

Se realizaron las modelaciones de las 12 combinaciones establecidas entre calidad de la subrasante y nivel de tránsito, cada una con dos alternativas, donde la primera corresponde a la estructura diseñada con un coeficiente estructural $a_{2}=0,12$ y la segunda a la estructura diseñada con un coeficiente estructural $a_{2}=0,17$. 


\subsection{ANÁLISIS DEFORMACIÓN PERMANENTE DE LA SUBRASANTE (MÉTODO SUDAFRICANO)}

Se aplicó la siguiente función de transferencia (South Afrian National Roads Agency LTD, 2013) para evaluar la deformación permanente de la subrasante:

$$
N_{P D}=10^{\left(a-10 * \log \varepsilon_{v}\right)} \quad \text { Ecuación } 11
$$

Donde " $N_{P D}$ " equivale al número de ejes estándar relacionados con el nivel de deformación permanente de la subrasante, y " $\varepsilon_{v}$ " corresponde a la deformación vertical por compresion en la parte superior de la subrasante, que en este caso equivale a los valores de Epsilon $Z$ calculados con el software DEPAV.

Por otra parte "a" representa una constante que depende de dos factores, siendo el primero el nivel de confiabilidad, que en este caso se asumió como el $90 \%$, y el segundo factor responde a la profundidad terminal que a su vez cuenta con dos opciones $10 \mathrm{~mm}$ y $20 \mathrm{~mm}$, para este caso se contempló el valor más común (South Afrian National Roads Agency LTD, 2013) que corresponde a $10 \mathrm{~mm}$, y por tanto el valor de "a" usado fue 33,37 . 


\section{CALCULOS Y RESULTADOS}

\subsection{DETERMINACIÓN DEL NÚMERO ESTRUCTURAL REQUERIDO (METODOLOGÍA AASHTO-93)}

Con base en los valores fijos de la Tabla 2, los valores de módulo resiliente para las cuatro categorías de subrasante y los valores ejes estándar de los tres niveles de tránsito, se remplazó en la fórmula básica de diseño y se calcularon los números estructurales $\left(S N_{0}\right)$ para cada uno de los doce casos evaluados, cuyos resultados fueron registrados en la Tabla 10.

Tabla 10. Números estructurales requeridos (SNO)

\begin{tabular}{|l|l|c|c|c|}
\hline \multicolumn{2}{|c|}{ SUBRASANTE } & \multicolumn{3}{c|}{ NIVEL DE TRANSITO } \\
\hline \multicolumn{2}{|c|}{ COMPORTAMIENTO } & $\begin{array}{c}\text { NT1 } \\
\text { (500 000 } \\
\text { ejes) }\end{array}$ & $\begin{array}{c}\text { NT2 } \\
\text { (5 000 000 } \\
\text { ejes) }\end{array}$ & $\begin{array}{c}\text { NT3 } \\
(10000 \text { 000 } \\
\text { ejes })\end{array}$ \\
\hline Malo & S1 (Mr=31,03 MPa) & 3,64 & 5,08 & 5,57 \\
\hline Regular & S2 (Mr=51,71 MPa) & 3,03 & 4,30 & 4,74 \\
\hline Bueno & S3 (Mr=103,42 MPa) & 2,35 & 3,38 & 3,75 \\
\hline Muy bueno & S4 (Mr=206,84 MPa) & 1,80 & 2,62 & 2,93 \\
\hline
\end{tabular}

Fuente: Autor

\subsection{DETERMINACIÓN NÚMERO ESTRUCTURAL (METODOLOGÍA AASHTO-93)}

A continuación con base en los valores estimados previamente para $a_{1}$ y $D_{1}$, se calculó el número estructural disponible de la carpeta asfáltica (SN1) como sigue:

SN1 $=0,41 * 3$ in

$$
S N 1=a_{1} * D_{1}
$$

Ecuación 12

$S N 1=1,23$ in 
Así mismo a partir de los dos valores tomados para $a_{2}$, y de los valores de $D_{2}$ y $m_{2}$, se calcularon los números estructurales disponibles (SN2 y SN2') para la base reciclada con cemento como sigue:

SN2 $=0,12 * 6$ in $* 1$

$$
S N 2=a_{2} * D_{2} * m_{2}
$$

Ecuación 13

SN2 $=0,72$ in

$S N 2^{\prime}=0,17 * 6$ in $* 1$

$$
S N 2^{\prime}=a_{2}^{\prime} * D_{2} * m_{2}
$$

Ecuación 14

$S N 2^{\prime}=1,02$ in

Igualmente de acuerdo a los valores seleccionados anteriormente para $a_{3}$ y $D_{3}$, se calculó el número estructural inicial disponible de la sub-base granular (SN3) como sigue:

$$
S N 3=a_{3} * D_{3} * m_{3} \quad \text { Ecuación } 15
$$

$S N 3=0,12 * 6$ in $* 1$

SN3 $=0,72$ in

Y sumando los valores de $\mathrm{SN}$ de cada capa, se calcularon los números estructurales totales disponibles. Siendo el SN para la estructura con $a_{2}=0,12$ el siguiente:

$$
S N=S N 1+S N 2+S N 3
$$

Ecuación 16

$S N=1,23+0,72+0,72$

$S N=2,67$ in 
$Y$ para la estructura con $a_{2}=0,17$ el siguiente:

$$
S N^{\prime}=S N 1+S N 2^{\prime}+S N 3
$$

$S N^{\prime}=1,23+1,02+0,72$

$S N^{\prime}=2,97$ in

\subsection{CÁlCULO ESPESOR AJUSTADO DE SUB-BASE GRANULAR $\left(D_{3} *\right)$}

En las Tablas 11 y 12 se registraron las alturas finales de SBG, donde los valores diferentes a $15,24 \mathrm{~cm}$ corresponden a las alturas $\left(D_{3} *\right)$ que debieron ser corregidas para alcanzar el $\mathrm{SN}$ requerido.

Tabla 11. Espesor final en $\mathrm{cm}$ de la $S B G$ para $S N$ requerido con a2=0,12

\begin{tabular}{|l|l|c|c|c|}
\hline \multicolumn{2}{|c|}{ SUBRASANTE } & \multicolumn{3}{c|}{ NIVEL DE TRANSITO } \\
\hline \multicolumn{2}{|c|}{ COMPORTAMIENTO } & $\begin{array}{c}\text { NT1 } \\
(500000 \\
\text { ejes })\end{array}$ & $\begin{array}{c}\text { NT2 } \\
(5000000 \\
\text { ejes })\end{array}$ & $\begin{array}{c}\text { NT3 } \\
(10000000 \\
\text { ejes })\end{array}$ \\
\hline Malo & S1 (Mr=31,03 MPa) & 35,74 & 66,16 & 76,65 \\
\hline Regular & S2 (Mr=51,71 MPa) & 22,85 & 49,66 & 59,09 \\
\hline Bueno & S3 (Mr=103,42 MPa) & 15,24 & 30,17 & 38,14 \\
\hline Muy bueno & S4 (Mr=206,84 MPa) & 15,24 & 15,24 & 20,67 \\
\hline
\end{tabular}

Fuente: Autor 
Tabla 12. Espesor final en $\mathrm{cm}$ de la $\mathrm{SBG}$ para $\mathrm{SN}$ requerido con a2=0,17

\begin{tabular}{|l|l|c|c|c|}
\hline \multicolumn{2}{|c|}{ SUBRASANTE } & \multicolumn{3}{c|}{ NIVEL DE TRANSITO } \\
\hline \multicolumn{2}{|c|}{ COMPORTAMIENTO } & $\begin{array}{c}\text { NT1 } \\
\text { (500 000 } \\
\text { ejes })\end{array}$ & $\begin{array}{c}\text { NT2 } \\
(5000000 \\
\text { ejes })\end{array}$ & $\begin{array}{c}\text { NT3 } \\
(10000000 \\
\text { ejes })\end{array}$ \\
\hline Malo & S1 (Mr=31,03 MPa) & 29,39 & 59,81 & 70,30 \\
\hline Regular & S2 (Mr=51,71 MPa) & 16,50 & 43,31 & 52,74 \\
\hline Bueno & S3 (Mr=103,42 MPa) & 15,24 & 23,82 & 31,79 \\
\hline Muy bueno & S4 (Mr=206,84 MPa) & 15,24 & 15,24 & 15,24 \\
\hline
\end{tabular}

Fuente: Autor

\subsection{MODELACIÓN EN EL SOFTWARE DEPAV}

En la Imagen 1 se ilustra una de las entradas de datos al programa, en este caso corresponde a la combinación subrasante $\mathrm{S} 1$ y nivel de transito NT1. Los valores usados para radio de carga, presión de contacto y distancia entre ejes de llantas, responden a los recomendados por los desarrolladores del programa y fueron empleados en todas las modelaciones.

La capa 1 equivale a la carpeta asfáltica, la capa 2 a la base reciclada con cemento, la capa 3 a la sub-base granular y la capa 4 a la subrasante. El valor de "E" responde al módulo resiliente, " $\mu$ " responde a la relación de Poisson y " $\mathrm{H}$ " se refiere a la altura de cada capa.

Igualmente se resaltan en la Imagen 5 los dos valores que se fueron cambiando en cada modelación, correspondientes al módulo resiliente de la subrasante y la altura de la sub-base granular, los demás valores permanecieron constantes. 


\section{Imagen 5.Datos de entrada DEPAV}

\begin{tabular}{|c|c|c|c|c|}
\hline \multicolumn{3}{|c|}{ Número de Capas [2..6] } & \multicolumn{2}{|l|}{4} \\
\hline Distanc & $\begin{array}{c}\text { Ra } \\
\text { Presión de } \\
\text { ia Entre Eje }\end{array}$ & $\begin{array}{l}\text { dio d } \\
\text { Conta } \\
\text { s de }\end{array}$ & $\begin{array}{l}\text { e Carga }[\mathrm{cm}] \\
\text { cto }\left[\mathrm{Kg} / \mathrm{cm}^{2}\right] \\
\text { Llantas }[\mathrm{cm}]\end{array}$ & $\begin{array}{l}10.8 \\
5.6 \\
32.4\end{array}$ \\
\hline Capas & $\mathrm{E}\left[\mathrm{Kg} / \mathrm{cm}^{2}\right]$ & $\mu$ & $H[\mathrm{~cm}]$ & ígada \\
\hline $\begin{array}{l}10 \\
2 \mathrm{a} \\
3 \mathrm{a} \\
4 \mathrm{a} \\
5 \mathrm{a} \\
6 \mathrm{a}\end{array}$ & $\begin{array}{l}26815.78 \\
50985.80 \\
1179.42 \\
316.38\end{array}$ & $\begin{array}{l}0.35 \\
0.25 \\
0.46 \\
0.45\end{array}$ & $\begin{array}{l}7.62 \\
15.24 \\
35.74\end{array}$ & $\begin{array}{l}\mathbf{L} \\
\mathbf{L} \\
\mathbf{L}\end{array}$ \\
\hline
\end{tabular}

Fuente: Autor.

Con los datos ingresados el programa presenta como salida una pantalla (Imagen 6 ) con los esfuerzos y deformaciones en cada capa. El valor de " $z$ " equivale a la distancia del punto evaluado respecto a la superficie de rodadura, "Épsilon T" equivale a la deformación unitaria por tensión, "Épsilon Z" equivale a la deformación unitaria por compresión, "Sigma T" equivale al esfuerzo por tensión, "Sigma Z" equivale al esfuerzo por compresión.

\section{Imagen 6. Resultados DEPAV}

\begin{tabular}{|c|c|c|c|c|c|}
\hline Capa & $\begin{array}{c}Z \\
(\mathrm{~cm})\end{array}$ & Epsilon $T$ & $\underset{\left\langle\mathrm{Kg} / \mathrm{cm}^{2}\right\rangle}{\mathrm{Sigma}}$ & Epsilon Z & $\underset{\left\langle\mathrm{Kg} / \mathrm{cm}^{2}\right\rangle}{\mathrm{Sigma}}$ \\
\hline $1 \%$ & $\begin{array}{l}0.00 \\
7.62\end{array}$ & $\begin{array}{l}1.3500 E-04 \mathrm{C} \\
4.4000 \mathrm{C}-05 \mathrm{C}\end{array}$ & $\begin{array}{l}8.0964 E+00 \text { B } \\
3.7525 E+09\end{array}$ & $\begin{array}{l}-1.0600 E-04 \\
-4.0800 E-05\end{array}$ & $\begin{array}{l}5.5982 E+00 ~ \\
4.4765 E+Q 0\end{array}$ \\
\hline 2 으 & $\begin{array}{r}7.62 \\
22.86\end{array}$ & $\begin{array}{r}4.4000 E-05 \mathrm{C} \\
-1.1900 \mathrm{C}-04 \mathrm{C}\end{array}$ & $\begin{array}{r}3.7423 E+00 \mathrm{~B} \\
-7.3112 \mathrm{E}+00 \mathrm{C}\end{array}$ & $\begin{array}{r}-2.4000 E-05 \\
7.0500 E-05\end{array}$ & $\begin{array}{l}4.4765 \mathrm{E}+0 \mathrm{~B} \\
3.1611 \mathrm{E}-01 \mathrm{C}\end{array}$ \\
\hline 3 으 & $\begin{array}{l}22.86 \\
58.68\end{array}$ & $\begin{array}{l}-1.19 Q \square E-04 c \\
-1.38 Q 0 E-04\end{array}$ & $\begin{array}{r}4.3541 E-03 \mathrm{C} \\
-1.9170 \mathrm{E}-01 \mathrm{C}\end{array}$ & $\begin{array}{l}2.5500 E-04 \\
2.2200 E-04\end{array}$ & $\begin{array}{l}3.1611 \mathrm{E}-01 \mathrm{C} \\
1.1217 \mathrm{E}-01 \mathrm{C}\end{array}$ \\
\hline $4 \%$ & 58.60 & $-1.3800 E-04 \mathrm{C}$ & $1.3766 \mathrm{E}-02 \mathrm{C}$ & $3.1100 \mathrm{G}-04 \mathrm{C}$ & 1.1217E-01 C \\
\hline \multicolumn{6}{|c|}{$\begin{array}{l}\text { Def lexión } \\
\text { Radio de Curuatura }=\end{array}$} \\
\hline
\end{tabular}

Fuente: Autor. 
De la información arrojada por el DEPAV, se tomaron los valores de las deformaciones unitarias verticales de compresion (Épsilon Z) en la subrasante y se elaboraron las Tablas 13 y 14.

Tabla 13. Épsilon $Z$ subrasante, con a2=0,12

\begin{tabular}{|l|l|c|c|c|}
\hline \multicolumn{2}{|c|}{ SUBRASANTE } & \multicolumn{3}{c|}{ NIVEL DE TRANSITO } \\
\hline \multicolumn{2}{|c|}{ COMPORTAMIENTO } & $\begin{array}{c}\text { NT1 } \\
(500 \text { 000 ejes })\end{array}$ & $\begin{array}{c}\text { NT2 } \\
(5000000 \\
\text { ejes })\end{array}$ & $\begin{array}{c}\text { NT3 } \\
10000000 \\
\text { ejes })\end{array}$ \\
\hline Malo & S1 (Mr=31,03 MPa) & $3,11 \mathrm{E}-04$ & $2,12 \mathrm{E}-04$ & $1,86 \mathrm{E}-04$ \\
\hline Regular & S2 (Mr=51,71 MPa) & $2,82 \mathrm{E}-04$ & $2,01 \mathrm{E}-04$ & $1,78 \mathrm{E}-04$ \\
\hline Bueno & S3 (Mr=103,42 MPa) & $2,08 \mathrm{E}-04$ & $1,70 \mathrm{E}-04$ & $1,53 \mathrm{E}-04$ \\
\hline Muy bueno & $\mathrm{S} 4(\mathrm{Mr}=206,84 \mathrm{MPa})$ & $1,28 \mathrm{E}-04$ & $1,28 \mathrm{E}-04$ & $1,18 \mathrm{E}-04$ \\
\hline
\end{tabular}

Fuente: Autor

Tabla 14. Épsilon $Z$ subrasante, con a2=0,17

\begin{tabular}{|l|l|c|c|c|}
\hline \multicolumn{2}{|c|}{ SUBRASANTE } & \multicolumn{3}{c|}{ NIVEL DE TRANSITO } \\
\hline \multicolumn{2}{|c|}{ COMPORTAMIENTO } & $\begin{array}{c}\text { NT1 } \\
(500000 \text { ejes })\end{array}$ & $\begin{array}{c}\text { NT2 } \\
(5000000 \\
\text { ejes })\end{array}$ & $\begin{array}{c}\text { NT3 } \\
(10000000 \\
\text { ejes })\end{array}$ \\
\hline Malo & S1 (Mr=31,03 MPa) & $3,36 E-04$ & $2,29 \mathrm{E}-04$ & $2,01 \mathrm{E}-04$ \\
\hline Regular & S2 (Mr=51,71 MPa) & $3,03 \mathrm{E}-04$ & $2,18 \mathrm{E}-04$ & $1,93 \mathrm{E}-04$ \\
\hline Bueno & S3 (Mr=103,42 MPa) & $2,08 \mathrm{E}-04$ & $1,86 \mathrm{E}-04$ & $1,67 \mathrm{E}-04$ \\
\hline Muy bueno & S4 (Mr=206,84 MPa) & $1,28 \mathrm{E}-04$ & $1,28 \mathrm{E}-04$ & $1,28 \mathrm{E}-04$ \\
\hline
\end{tabular}

Fuente: Autor

Para ilustrar el comportamiento de la deformación vertical de compresión en la subrasante respecto a su módulo resiliente se realizó la Grafica 1 representando las deformaciones generadas con cada nivel de tránsito. 


\section{Gráfica 1. Deformación vertical en la subrasante.}

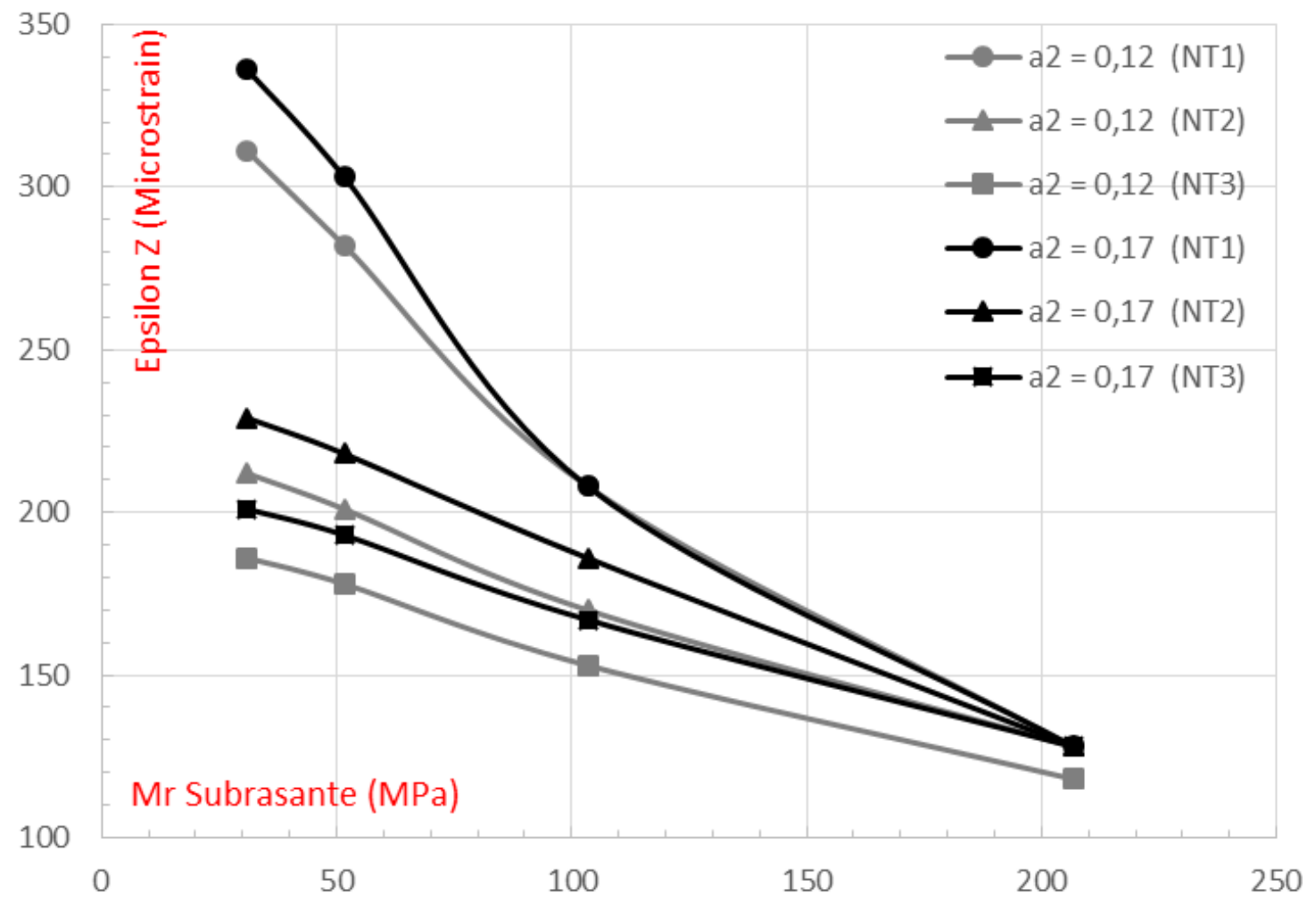

Fuente: Autor

Por otra parte realizaron las Tablas 15 y 16 con los valores de esfuerzo de compresión (Sigma Z) en la subrasante, para las diferentes combinaciones simuladas.

Tabla 15. Sigma Z (kg/cm2) subrasante, con a2=0,12

\begin{tabular}{|l|l|c|c|c|}
\hline \multicolumn{2}{|c|}{ SUBRASANTE } & \multicolumn{3}{c|}{ NIVEL DE TRANSITO } \\
\hline \multicolumn{2}{|c|}{ COMPORTAMIENTO } & $\begin{array}{c}\text { NT1 } \\
(500000 \text { ejes })\end{array}$ & $\begin{array}{c}\text { NT2 } \\
(5000000 \\
\text { ejes })\end{array}$ & $\begin{array}{c}\text { NT3 } \\
10000000 \\
\text { ejes })\end{array}$ \\
\hline Malo & S1 (Mr=31,03 MPa) & $1,122 \mathrm{E}-01$ & $7,169 \mathrm{E}-02$ & $6,230 \mathrm{E}-02$ \\
\hline Regular & S2 (Mr=51,71 MPa) & $1,774 \mathrm{E}-01$ & $1,173 \mathrm{E}-01$ & $1,020 \mathrm{E}-01$ \\
\hline Bueno & S3 (Mr=103,42 MPa) & $2,814 \mathrm{E}-01$ & $2,152 \mathrm{E}-01$ & $1,886 \mathrm{E}-01$ \\
\hline Muy bueno & S4 (Mr=206,84 MPa) & $3,732 \mathrm{E}-01$ & $3,732 \mathrm{E}-01$ & $3,324 \mathrm{E}-01$ \\
\hline
\end{tabular}

Fuente: Autor 
Tabla 16. Sigma $Z(\mathrm{~kg} / \mathrm{cm} 2)$ subrasante, con a2=0,17

\begin{tabular}{|l|l|c|c|c|}
\hline \multicolumn{2}{|c|}{ SUBRASANTE } & \multicolumn{3}{c|}{ NIVEL DE TRANSITO } \\
\hline \multicolumn{2}{|c|}{ COMPORTAMIENTO } & $\begin{array}{c}\text { NT1 } \\
(500000 \text { ejes })\end{array}$ & $\begin{array}{c}\text { NT2 } \\
(5000000 \\
\text { ejes })\end{array}$ & $\begin{array}{c}\text { NT3 } \\
(10000000 \\
\text { ejes })\end{array}$ \\
\hline Malo & S1 (Mr=31,03 MPa) & $1,234 \mathrm{E}-01$ & $7,831 \mathrm{E}-02$ & $6,781 \mathrm{E}-02$ \\
\hline Regular & $\mathrm{S} 2(\mathrm{Mr}=51,71 \mathrm{MPa})$ & $1,968 \mathrm{E}-01$ & $1,285 \mathrm{E}-01$ & $1,122 \mathrm{E}-01$ \\
\hline Bueno & $\mathrm{S} 3(\mathrm{Mr}=103,42 \mathrm{MPa})$ & $2,814 \mathrm{E}-01$ & $2,407 \mathrm{E}-01$ & $2,090 \mathrm{E}-01$ \\
\hline Muy bueno & $\mathrm{S} 4(\mathrm{Mr}=206,84 \mathrm{MPa})$ & $3,732 \mathrm{E}-01$ & $3,732 \mathrm{E}-01$ & $3,732 \mathrm{E}-01$ \\
\hline
\end{tabular}

Fuente: Autor

Para representar el comportamiento del esfuerzo de compresión en la subrasante respecto a su módulo resiliente se realizó la Grafica 2.

\section{Gráfica 2. Esfuerzo de compresión en subrasante.}

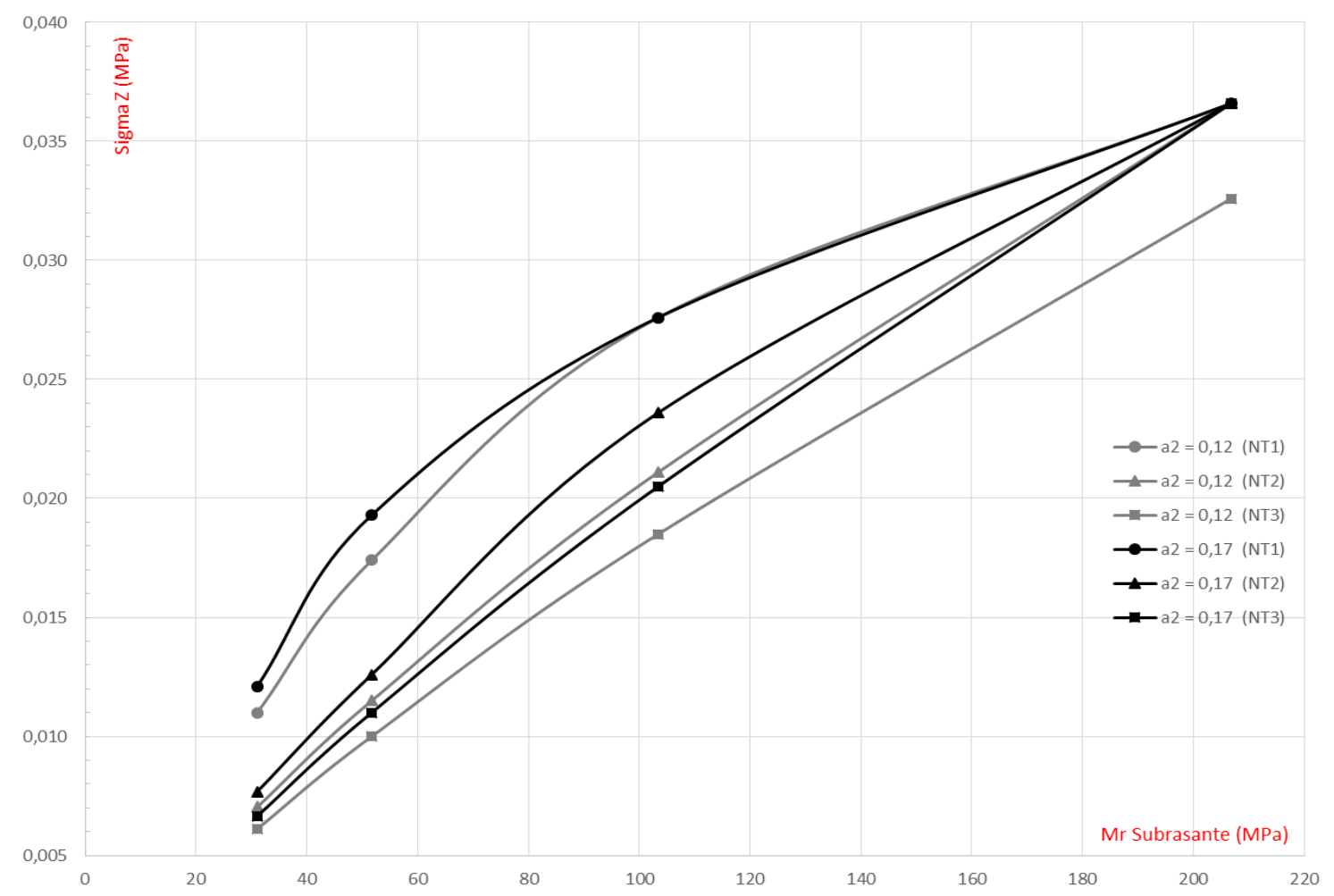

Fuente: Autor 
Igualmente se realizaron las Tablas 17 y 18 con los valores de esfurerzo de tracción (Sigma T) en la parte inferior de la base reciclada con cemento, para todas las combinaciones simuladas.

Tabla 17. Sigma $T(\mathrm{~kg} / \mathrm{cm} 2)$ en base reciclada con cemento, con a2=0,12

\begin{tabular}{|l|l|c|c|c|}
\hline \multicolumn{2}{|c|}{ SUBRASANTE } & \multicolumn{3}{c|}{ NIVEL DE TRANSITO } \\
\hline \multicolumn{2}{|c|}{ COMPORTAMIENTO } & $\begin{array}{c}\text { NT1 } \\
(500 \text { 000 ejes })\end{array}$ & $\begin{array}{c}\text { NT2 } \\
\left(\begin{array}{c}000000 \\
\text { ejes })\end{array}\right.\end{array}$ & $\begin{array}{c}\text { NT3 } \\
(10000000 \\
\text { ejes })\end{array}$ \\
\hline Malo & S1 (Mr=31,03 MPa) & 7,3112 & 6,7300 & 6,6179 \\
\hline Regular & S2 (Mr=51,71 MPa) & 7,1277 & 6,6790 & 6,5873 \\
\hline Bueno & S3 (Mr=103,42 MPa) & 6,4139 & 6,3527 & 6,3323 \\
\hline Muy bueno & S4 (Mr=206,84 MPa) & 5,6389 & 5,6389 & 5,7307 \\
\hline
\end{tabular}

Fuente: Autor

Tabla 18. Sigma $T(\mathbf{k g} / \mathrm{cm} 2)$ en base reciclada con cemento, con a2=0,17

\begin{tabular}{|l|l|c|c|c|}
\hline \multicolumn{2}{|c|}{ SUBRASANTE } & \multicolumn{3}{c|}{ NIVEL DE TRANSITO } \\
\hline \multicolumn{2}{|c|}{ COMPORTAMIENTO } & $\begin{array}{c}\text { NT1 } \\
(500000 \text { ejes })\end{array}$ & $\begin{array}{c}\text { NT2 } \\
(5000000 \\
\text { ejes })\end{array}$ & $\begin{array}{c}\text { NT3 } \\
(10000000 \\
\text { ejes })\end{array}$ \\
\hline Malo & $\mathrm{S} 1(\mathrm{Mr}=31,03 \mathrm{MPa})$ & 7,5050 & 6,8116 & 6,6790 \\
\hline Regular & $\mathrm{S} 2(\mathrm{Mr}=51,71 \mathrm{MPa})$ & 7,3011 & 6,7606 & 6,6484 \\
\hline Bueno & $\mathrm{S} 3(\mathrm{Mr}=103,42 \mathrm{MPa})$ & 6,4139 & 6,3731 & 6,3527 \\
\hline Muy bueno & $\mathrm{S} 4(\mathrm{Mr}=206,84 \mathrm{MPa})$ & 5,6389 & 5,6389 & 5,6389 \\
\hline
\end{tabular}

Fuente: Autor

Como complemento, en la Grafica 3 se muestra como ejemplo el comportamiento del esfuerzo de traccion en parte inferior de la base reciclada con cemento para cada uno de los niveles de transito. 


\section{Gráfica 3. Esfuerzo de tracción en BRC.}

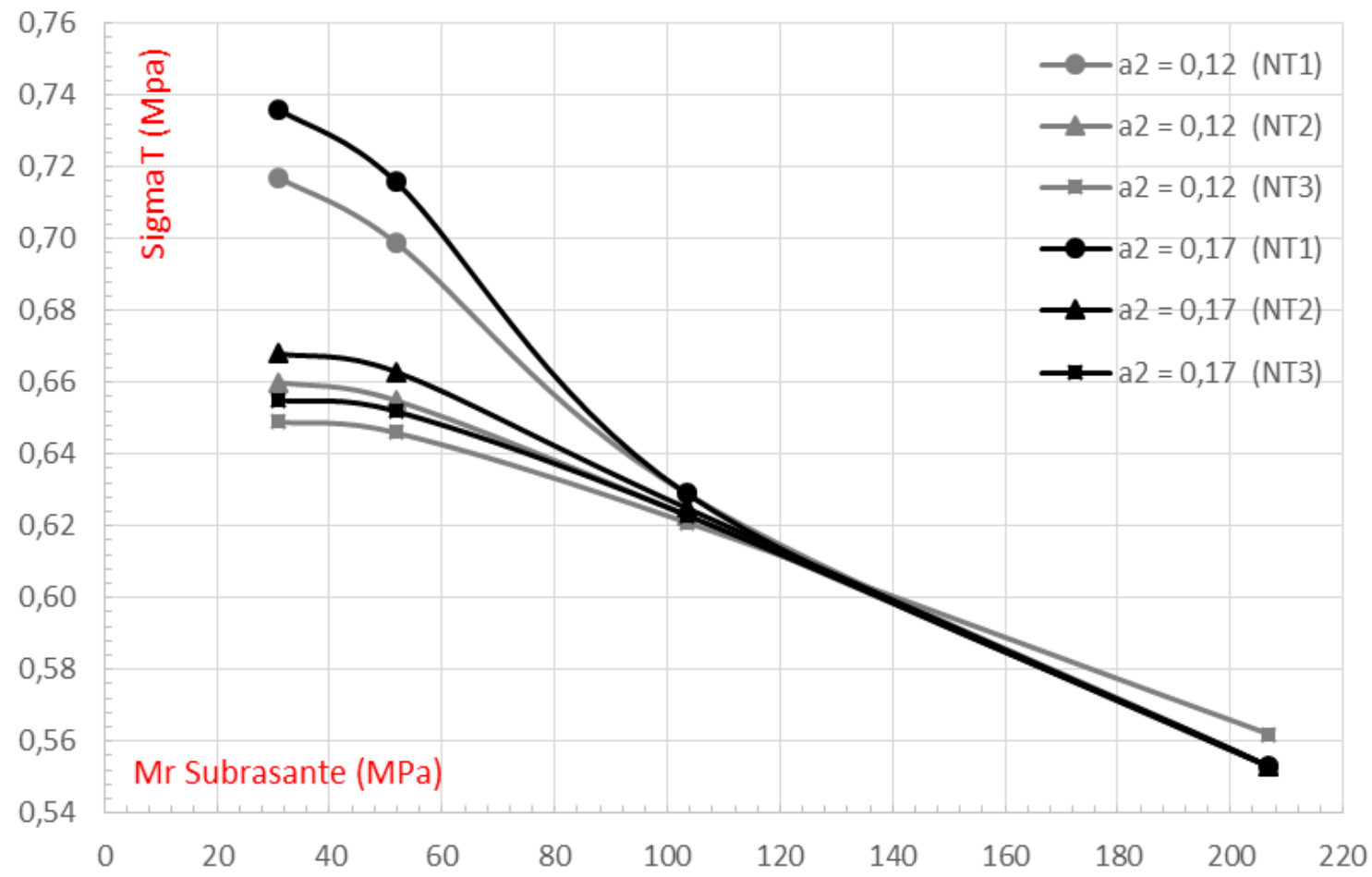

Fuente: Autor

Finalmente se elaboraron las Tablas 19 y 20 con los resultados de deformacion de tracción (Epsilon T) calculados en la parte inferior de la base reciclada con cemento, para todas las combinaciones simuladas, y se realizo la Grafica 4 para visualizar dichos resultados.

Tabla 19. Epsilon $T$ en base reciclada con cemento, con a_2 $\mathbf{2} \mathbf{0 , 1 2}$

\begin{tabular}{|l|l|c|c|c|}
\hline \multicolumn{2}{|c|}{ SUBRASANTE } & \multicolumn{3}{c|}{ NIVEL DE TRANSITO } \\
\hline \multicolumn{2}{|c|}{ COMPORTAMIENTO } & $\begin{array}{c}\text { NT1 } \\
(500000 \text { ejes })\end{array}$ & $\begin{array}{c}\text { NT2 } \\
(5000000 \\
\text { ejes })\end{array}$ & $\begin{array}{c}\text { NT3 } \\
(10000000 \\
\text { ejes })\end{array}$ \\
\hline Malo & S1 (Mr=31,03 MPa) & $1,190 \mathrm{E}-04$ & $1,100 \mathrm{E}-04$ & $1,090 \mathrm{E}-04$ \\
\hline Regular & S2 (Mr=51,71 MPa) & $1,160 \mathrm{E}-04$ & $1,100 \mathrm{E}-04$ & $1,080 \mathrm{E}-04$ \\
\hline Bueno & S3 (Mr=103,42 MPa) & $1,060 \mathrm{E}-04$ & $1,050 \mathrm{E}-04$ & $1,050 \mathrm{E}-04$ \\
\hline Muy bueno & S4 (Mr=206,84 MPa) & $9,480 \mathrm{E}-05$ & $9,480 \mathrm{E}-05$ & $9,620 \mathrm{E}-05$ \\
\hline
\end{tabular}

Fuente: Autor 
Tabla 20. Epsilon T en base reciclada con cemento, con a_2 $\mathbf{2} \mathbf{0 , 1 7}$

\begin{tabular}{|l|l|c|c|c|}
\hline \multicolumn{2}{|c|}{ SUBRASANTE } & \multicolumn{3}{c|}{ NIVEL DE TRANSITO } \\
\hline \multicolumn{2}{|c|}{ COMPORTAMIENTO } & $\begin{array}{c}\text { NT1 } \\
(500000 \text { ejes })\end{array}$ & $\begin{array}{c}\text { NT2 } \\
(5000000 \\
\text { ejes })\end{array}$ & $\begin{array}{c}\text { NT3 } \\
(10000000 \\
\text { ejes })\end{array}$ \\
\hline Malo & S1 (Mr=31,03 MPa) & $1,220 \mathrm{E}-04$ & $1,120 \mathrm{E}-04$ & $1,100 \mathrm{E}-04$ \\
\hline Regular & $\mathrm{S} 2(\mathrm{Mr}=51,71 \mathrm{MPa})$ & $1,190 \mathrm{E}-04$ & $1,110 \mathrm{E}-04$ & $1,090 \mathrm{E}-04$ \\
\hline Bueno & $\mathrm{S} 3(\mathrm{Mr}=103,42 \mathrm{MPa})$ & $1,060 \mathrm{E}-04$ & $1,050 \mathrm{E}-04$ & $1,050 \mathrm{E}-04$ \\
\hline Muy bueno & $\mathrm{S} 4(\mathrm{Mr}=206,84 \mathrm{MPa})$ & $9,480 \mathrm{E}-05$ & $9,480 \mathrm{E}-05$ & $9,480 \mathrm{E}-05$ \\
\hline
\end{tabular}

Fuente: Autor

Gráfica 4. Deformacion de tracción en BRC.

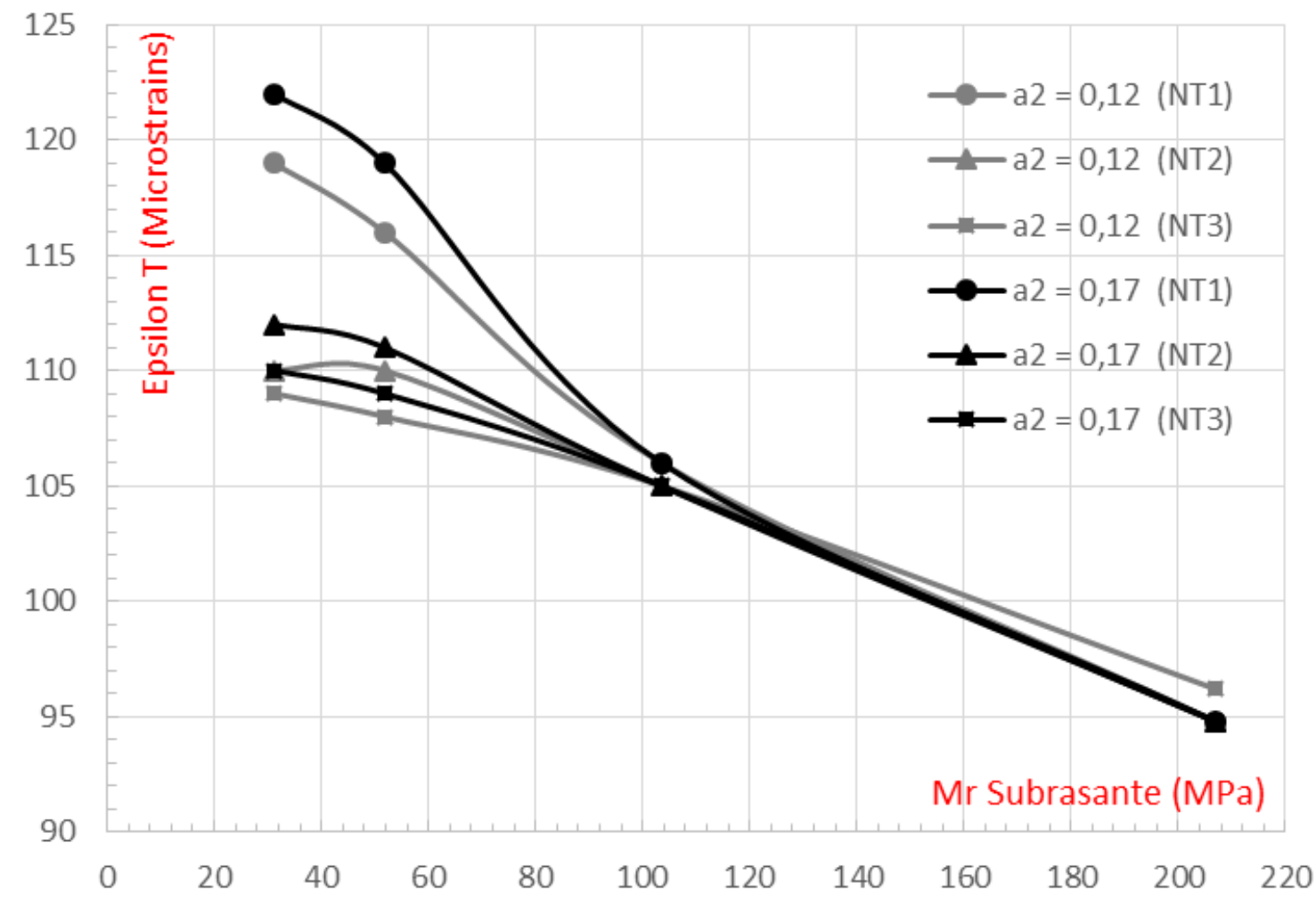

Fuente: Autor 


\subsection{ANÁLISIS DE LA DEFORMACIÓN PERMANENTE DE LA SUBRASANTE (MÉTODO SUDAFRICANO)}

Los valores de deformación unitaria de la subrasante "Epsilon Z" (Tablas 13 y 14) extraidos del DEPAV, fueron evaluados en la función de transferencia Sudafricana (South Afrian National Roads Agency LTD, 2013) para analizar la deformación permanente de la subrasante. Los valores de $N_{P D}$ calculados se presentan en las Tablas 21 y 22.

Tabla 21. Valores de N_PD (millones), con a_2=0,12

\begin{tabular}{|l|l|r|r|r|}
\hline \multicolumn{2}{|c|}{ SUBRASANTE } & \multicolumn{3}{c|}{ NIVEL DE TRANSITO } \\
\hline \multicolumn{2}{|c|}{ COMPORTAMIENTO } & $\begin{array}{c}\text { NT1 } \\
\text { (500 000 ejes) }\end{array}$ & $\begin{array}{c}\text { NT2 } \\
\text { (5 000 000 } \\
\text { ejes })\end{array}$ & $\begin{array}{c}\text { NT3 } \\
(10000000 \\
\text { ejes })\end{array}$ \\
\hline Malo & S1 (Mr=31,03 MPa) & 349 & 16093 & 59548 \\
\hline Regular & S2 (Mr=51,71 MPa) & 928 & 27418 & 92427 \\
\hline Bueno & S3 (Mr=103,42 MPa) & 19470 & 146390 & 419842 \\
\hline Muy bueno & S4 (Mr=206,84 MPa) & 2499771 & 2499771 & 5638712 \\
\hline
\end{tabular}

Fuente: Autor

Tabla 22. Valores de N_PD (millones), con a2 $=0,17$

\begin{tabular}{|l|l|r|r|r|}
\hline \multicolumn{2}{|c|}{ SUBRASANTE } & \multicolumn{3}{c|}{ NIVEL DE TRANSITO } \\
\hline \multicolumn{2}{|c|}{ COMPORTAMIENTO } & $\begin{array}{c}\text { NT1 } \\
\text { (500 000 ejes })\end{array}$ & $\begin{array}{c}\text { NT2 } \\
\text { (5 000 000 } \\
\text { ejes })\end{array}$ & $\begin{array}{c}\text { NT3 } \\
\text { (10 000 000 } \\
\text { ejes })\end{array}$ \\
\hline Malo & S1 (Mr=31,03 MPa) & 161 & 7441 & 27418 \\
\hline Regular & S2 (Mr=51,71 MPa) & 452 & 12174 & 41155 \\
\hline Bueno & S3 (Mr=103,42 MPa) & 19470 & 59548 & 174918 \\
\hline Muy bueno & S4 (Mr=206,84 MPa) & 2499771 & 2499771 & 2499771 \\
\hline
\end{tabular}

Fuente: Autor

Igualmente se realizaron las Gráficas 5 y 6 para visualizar el comportamiento del número de ejes equivalentes respecto a la deformación de compresión en la subrasante. 
Gráfica 5. N_PD vs Deformacion vertical subrasante $\left(a \_2=0,12\right)$

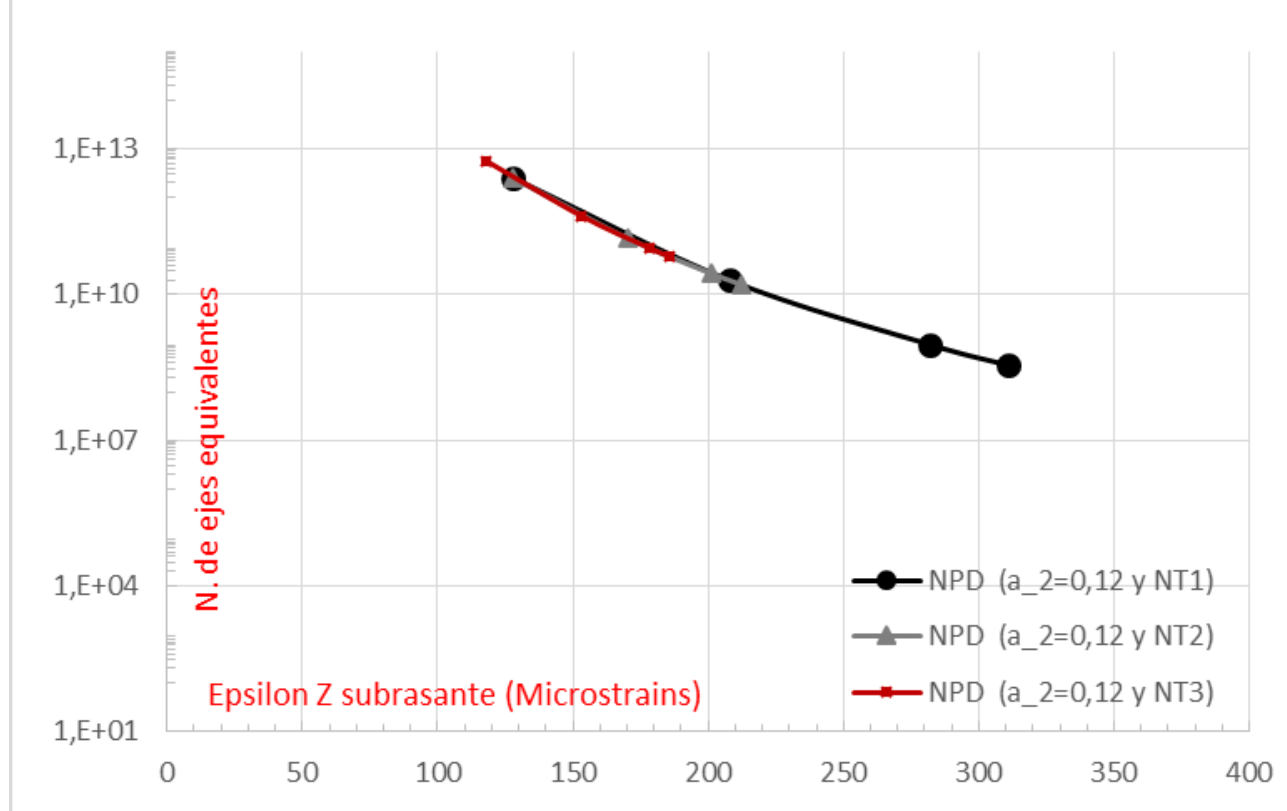

Fuente: Autor

Gráfica 6. N_PD vs Deformacion vertical subrasante $\left(a \_2=0,17\right)$

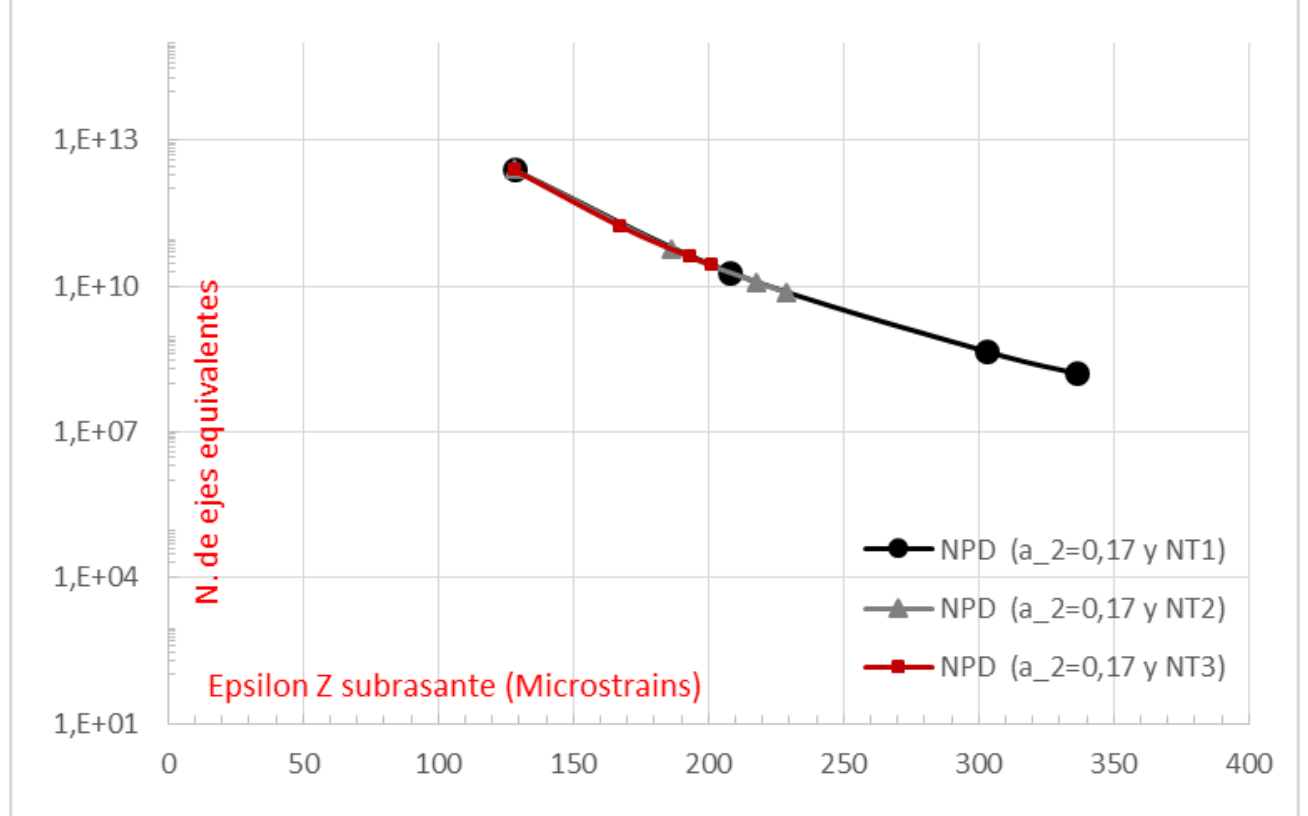

Fuente: Autor 


\section{ANALISIS DE RESULTADOS}

Con los resultados de la aplicación de la metodologia AASHTO, en la Tabla 10 se aprecia como los valores de número estructural obtenidos a partir de la ecuación básica de diseño van siendo mayores a medida que aumenta el nivel de tránsito, es decir el número de ejes estándar de diseño. Así mismo se evidencia el requerimiento de un mayor número estructural para el pavimento a medida que el comportamiento de la subrasante va desmejorando, encontrando como valor más crítico 5,57", correspondiente a una subrasante de comportamiento malo (S1) y a un nivel de transito 3 (10 millones de ejes).

En el diseño de las estructuras de pavimento se usaron dos coeficientes estructurales $(0,12$ y 0,17$)$ para la capa de base reciclada en frío con cemento, por lo cual se obtuvieron dos números estructurales, los cuales se relacionan directamente con los coeficientes usados, tal que para el coeficiente de 0,12 se obtuvo un numero estructural de 0,72 ", menor que el obtenido con el coeficiente de 0,17 cuyo valor fue $1,02 "$. Así mismo se evidenció la relación directa existente entre la resistencia a compresión incofinada del material con respecto a su aporte estructural, como en este caso donde el mayor aporte estructural fue dado por el material con mayor coeficiente y mayor resistencia a compresión incofinada. Lo anterior basado en la informacion encontrada en la "Guía para el diseño de obras de rehabilitación de pavimentos" del INVIAS, donde se menciona que a partir de la experiencia el valor de coeficiente de 0,12 se relaciona con una compresión inconfinada menor a $1 \mathrm{MPa}$, y el coeficiente de 0,17 con una compresión inconfinada de entre 1 y 3 Mpa.

El número estructural total disponible por tratarse de la suma de los números estructurales de cada una de las tres capas se ve directamente afectado por el valor de los coeficientes estructurales de las mismas, por tanto el número estructural total disponible calculado con el coeficiente $a_{2}=0,12$ obtuvo un valor de 2,67", menor que el 2,97" alcanzado usando el coeficiente $a_{2}{ }^{\prime}=0,17$.

Con base en lo anterior es claro que las estructuras diseñadas con un coeficiente $a_{2}=0,12$ con valores de numero estructural menor que los alcanzados con el coeficiente de $a_{2}{ }^{\prime}=0,17$, necesitaron valores mayores de sub-base granular como se observa en las Tablas 11 y 12, para alcanzar los números estructurales requeridos calculados con la formula básica de diseño AASHTO.

Así mismo en las Tablas 11 y 12 se puede apreciar que cuando el comportamiento de la subrasante es muy bueno el ajuste en la altura de la sub-base granular es 
mínimo o no requiere, e inclusive se podría pensar en disminuir su espesor, pero por temas constructivos se debe dejar el mínimo recomendado que es de $15 \mathrm{~cm}$.

Para verificar la capacidad estructural de la subrasante se analizaron el esfuerzo (Sigma Z) y la deformación (Epsilon Z) de compresión en esta capa, a partir de los resultados obtenidos en el software DEPAV. Al respecto, en las Tablas 13 y 14 se evidencia un aumento en la deformación vertical de la subrasante a medida que el espesor de la capa de sub-base granular es menor, observando mayores deformaciones para el nivel de transito 1 ya que por corresponderle una cantidad pequeña de ejes estándar en el diseño requirió un menor número estructural y por ende menor espesor de sub-base granular ajustada.

Por otra parte en las Tablas 13 y 14 tambien se puede apreciar como la deformación vertical en la subrasante aumenta a medida que el comportamiento de ésta empeora, lo cual también se puede apreciar en la Grafica 1 donde se observa que a medida que la calidad de la subrasante, expresada con su valor de módulo resiliente, va aumentando, la deformación vertical disminuye en la subrasante.

En cuanto al esfuerzo de compresión en la subrasante (Sigma Z), en las Tablas 15 y 16 se evidencia que éste esfuerzo aumenta a medida que la subrasante presenta un mejor comportamiento. En la Grafica 2 se muestra éste fenómeno, donde claramente se oberva que mientras la calidad de la subrasante mejora (mayor módulo resiliente), los esfuerzos verticales de compresión aumentan.

Así mismo a partir de las Tablas 15 y 16 se encontro que a mayor nivel de transito se presentaron menores valores de "Sigma Z", y que a menores espesores de subbase granular se generaron mayores esfuerzos de compresión en la subrasante.

Con la evaluación de la función de transferencia Sudafricana para analizar la deformación permanente de la subrasante, se encontró que los valores de las Tablas 21 y 22 correspondientes al número de ejes estándar $\left(N_{P D}\right)$ calculados en función de la deformación vertical (Épsilon Z) en dicha capa y una constante "a" dada, resultaron bastante superiores o los contemplados en el diseño AASHTO $(0,5$, 5 y 10 millones). Al respecto se ha encontrado que el número de ejes estándar de diseño de un pavimento con base cementada es muy superior, aproximadamente 21 veces, al valor de diseño para un pavimento flexible tradicional (Instituto Nacional de Vías de Colombia, 2008), pero en este caso los valores de ejes estandar obtenidos fueron demasiado grandes, por ejemplo 30, 80 y hasta más de 100 veces en muchos casos, por tanto se puede establecer que los diseños elaborados por metodología AASHTO pueden estar sobredimensionados para las deformaciones verticales estimadas que presentaría la subrasante y las cuales fueron obtenidas con la modelación en DEPAV. 
Por otro lado para evaluar la capa de base reciclada con cemento se analizaron los esfuerzos de tracción en la parte inferior de la capa (Sigma T), valores extraídos de la modelación en el software DEPAV. Referente a ello se puede apreciar en las Tablas 17 y 18 que se presentaron mayores esfuerzos de tensión en dicha capa, a medida que la subrasante de la estructura tenía una menor calidad, represenada como el valor de su módulo resiliente en la Grafica 3. Así mismo en éstas Tablas es evidente que se presentaron mayores esfuerzos "Sigma T" en cuanto los espesores de sub-base granular de la estructura eran menores.

Igualmente respecto a la base reciclada con cemento (BRC) se puede apreciar en las Tablas 19 y 20 que la deformación de tracción en la fibra inferior de la capa (Epsilon T) tiende a aumentar mientras la subrasante va desmejorando su comportamiento. Asi mismo se aprecia la tendencia de crecimiento de Epsilon T a medida que se cuenta con un menor espesor de sub-base granular en la estructura. 


\section{CONCLUSIONES Y RECOMENDACIONES}

\subsection{METODOLOGÍA AASHTO}

La metodología de la guía AASHTO se basa en la aplicación de una formula básica de diseño para determinar el aporte estructural (requerido) del pavimento flexible mediante un valor denominado "numero estructural" (SN) y que debe corresponder a la suma de los aportes estructurales de cada una de las tres capas del pavimento básico, determinados mediante el producto de tres factores: Espesor, coeficiente estructural y coeficiente de drenaje.

El número estructural (SN) de un pavimento flexible depende de una serie de parametros de diseño que deben ser estipulados en cada caso particullar, para garantizar que la estructura cumpla con el ciclo de vida esperado en un lugar determinado. Por ello es de suma importancia tener en cuenta dichos aspectos relacionados a continuacion: El modulo resiliente de la subrasante, el número de ejes estándar de diseño, el índice de serviciabilidad, las condiciones ambientales y de drenaje, y la confiabilidad.

En el diseño de un pavimento es indispensable contar con la mayor informacion posible correspondiente a la calidad de la subrasante (Modulo resiliente), ya que con esta investigación se encontró que al contar con mejores materiales de subrasante (buena y muy buena) se requieren menores espesores de sub-base granular, en la mayoría de los casos los minimos. Mientras que con subrasantes de baja calidad (regular y mala) se requieren espesores de sub-base granular de dos a tres veces los requeridos con una subrasante de buena calidad.

De otra parte se encontró que a medida que aumenta el numero de ejes de diseño se requieren mayores espesores de sub-base granular, ya que la estructura requiere de un mayor aporte estructural, encontrando valores hasta de $70 \mathrm{~cm}$ para un nivel de transito 3, lo cual no corresponde con lo esperado. Por tanto se recomienda contemplar estrategias de mejoramiento de la subrasantte a medida que se estimen mayores números de ejes en el diseño con el fin de obtener menores espesores de base o sub-base granular (si tiene) en la estructura.

Con los resultados obtenidos, se encontró que el numero estructural (SN) brindado por el pavimento fue directamente proporcional al coeficiente $a_{2}$ usado en el diseño, es decir que la capa tiende a generar un menor aporte estrucural (SN2) a medida que su coeficiente estructural disminuye. Por lo anterior lo ideal es trabajar con los 
materiales con mejores caracteristicas (modulo resiliente, resistencia a compresión incofinada) para requerir menores espesores.

Con base en que el numero estructural (SN) corresponde a la suma de los aportes estructurales de las capas del pavimento, se concluye que a medida que cada capa cuenta con mejores caractristicas en cuanto a coeficiente estructural $\left(a_{i}\right)$ y coeficiente de drenaje $\left(m_{i}\right)$, requerirá de un menor espesor $\left(D_{i}\right)$

\subsection{MODELACION DEPAV}

\subsubsection{Subrasante}

Se encontró que existe una tendencia de aumento de la deformación vertical (Epsilon Z) en la subrasante debido a dos factores principalmente: El primero se refiere a la disminución del espesor de la sub-base granular en función del numero de ejes de diseño, y el segundo al desmejoramiento de la calidad de la subrasante desde el punto de vista de su modulo resiliente.

Asi mismo que pudo determinar que el esfuerzo de compresión en la subrasante aumenta a medida que mejora el comportamiento de la misma y a medida que el número de ejes de diseño disminuye, representado en menores espesores de subbase granular.

A partir de los resultados obtenidos con las modelaciones en el software, se concluye que tanto la deformación como el esfuerzo vertical de compresión en la subrasante obtuvieron mayores valores usando el coeficiente estructural $a_{2}=0,17$ que usando el coeficiente estructural de 0,12.

\subsubsection{Base reciclada con cemento (BRC)}

Con base en los resultados obtenidos en el programa, se concluye que existe una inclinación hacia el crecimiento de la deformación de traccion (Epsilon T) y del esfuerzo de tracción (Sigma T) en ésta capa, primero a medida que se deteriora el comportamiento de la subrasante, y segundo con la disminución del espesor de subbase granular. 
Asi mismo, se concluye que tanto la deformación como el esfuerzo de tracción de la base reciclada con cemento obtuvieron mayores valores usando el coeficiente estructural $a_{2}=0,17$ que usando el coeficiente estructural de 0,12.

\subsection{DEFORMACION PERMANENTE DE LA SUBRASANTE - METODOLOGÍA SUDAFRICANA}

Con la aplicación de la función de transferencia Sudafricana para analizar la deformación vertical en la subrasante y teniendo en cuenta la literatura consultada, se esperaban resultados alrededor de 21 veces el número de ejes contemplados en el diseño, pero se obtuvieron valores de mas de 60 veces el numero de ejes. Es decir que las deformaciones en la subrasante que son del orden de magnitud a la menos 4 , son muy pequeñas y por ende desde el punto de vista de la metodología Sudafricana las estructuras analizadas tendrían la capacidad de soportar muchos mas ejes equivalentes, lo cual conlleva a estimar que con el diseño por AASHTO en algunos casos como los estudiados en esta investigacion, se pueden estar sobredimensionando las diferentes capas de la estructura.

\subsection{RECOMENDACIONES}

Se espera que este trabajo sirva como punto de partida para futuras investigaciones en el campo del estudio del comportamiento de los materiales reciclados con cemento y su interaccion con la deformación permanente de la subrasante.

Se recomienda realizar modelaciones con otros programas de diseño de pavimentos para comparar los resultados obtenidos mediante el softwarel DEPAV, y establecer las ventajas y desventajas del software en comparación con los mismos, e identificando cual de éstos brinda unos resultados menos sobredimensionados al diseñar un pavimento.

Asi mismo se recomienda analizar en futuras investigaciones la deformación permanente de pavimentos con capas estabilizadas con cemento a través de otros modelos de daño y comparar con los resultados obtenidos mediante el método Sudafricano. 
Por otro lado se sugiere continuar con nuevas investigaciones sobre el comportamiento estructural de pavimentos con capas estabilizadas con cemento, con el fin de ampliar el conocimiento entre los estudiantes y profesionales involucrados en el tema, para generar nuevo material de consulta que trascienda en innovación y generación de nuevos procesos en búsqueda de resaltar la necesidad de la creación de nuevos documentos técnicos nacionales que incluyan este tipo de materiales que representan no solo un ahorro en costos sino un beneficio para el medio ambiente. 


\section{BIBLIOGRAFIA}

Adresi, M., khishdari, A., Ahmadi, A., \& Rooholamini, H. (2017). Influence of high content of reclaimed asphalt on the mechanical properties of cement-treated base under critical environmental conditions. International Journal of Pavement Engineering, 8436(October), 1-8. https://doi.org/10.1080/10298436.2017.1388508

American Association of State Highway and Transportation Offcials. (1993). AASHTO Guide for Design of Pavement Structures 1993. Washington D.C.

Barrera, E., \& Olmedo, O. (2015). Utilización de residuos de construcción y demolición $(R C D)$ ligados con materiales cementantes en pavimentos. Pontificia Universidad Javeriana.

Burbano, J., \& Zuluaga, D. (2011). Influencia de la granulometría y la dosificacion en el desempeño del fresado estabilizado con emulsión asfáltica. Universidad Javeriana.

Cardoso, V. (2016). Evaluacion de mezclas asfálticas en frio con pavimento reciclado utilizando diferentes dosificaciones y tiempos de curado. Universidad de los Andes.

CEDEX. (2011). Reciclado de pavimentos asfalticos. Retrieved from http://www.cedex.es/NR/rdonlyres/26C518BE-1802-4803-82B1FBE634B03B03/119932/RECICLADODEPAVIMENTOSASFALTICOS.pdf

Consoli, N. C., Pasche, E., Specht, L., \& Tanski, M. (2017). Key parameters controlling dynamic modulus of crushed reclaimed asphalt paving-powdered rock-Portland cement blends. Road Materials and Pavement Design, 19(8), 1716-1733. https://doi.org/10.1080/14680629.2017.1345779

Department of Transport Republic of South Africa. (1996). TRH4: Structural Design of Flexible Pavements for Interurban and Rural Roads. In Africa. 
Descalzi, F., Cesar, J., Céspedes, C., Descalzi, F., Céspedes, C., \& Diseño, M. (2017). Diseño estructural de un pavimento básico reciclado y mejorado con cemento portland para diferentes dosificaciones en el proyecto de conservación vial de Huancavelica.

Fedrigo, W., Núñez, W., Castañeda, M., Kleinert, T., \& Ceratti, J. (2018). A study on the resilient modulus of cement-treated mixtures of RAP and aggregates using indirect tensile, triaxial and flexural tests. Construction and Building Materials, 171, 161-169. https://doi.org/10.1016/j.conbuildmat.2018.03.119

Hernández, P. (2014). Evaluación del comportamiento mecánico de mezclas asfálticas utilizando pavimento reciclado, ligantes hidráulicos y emulsiones asfálticas (Universidad Nacional de Colombia). Retrieved from http://www.bdigital.unal.edu.co/50476/

Higuera, C. (2007). Manuales de mecánica de pavimentos. Tunja: Universidad Pedagógia y Tecnológica de Colombia.

Instituo Mexicano del Transporte. (2001). Módulos de resiliencia en suelos finos y materiales granulares.

Instituto de Desarollo Urbano de Bogota D.C. (2011a). Sección 454 11-Reciclaje de pavimento asfáltico en el sitio con cemento pórtland. In Especificaciones técnicas generales de materiales y construccion para proyectos de infraestructura víal y de espacio público para Bogotá D.C.

Instituto de Desarollo Urbano de Bogota D.C. (2011b). Sección 540 11-Fresado de pavimentos asfálticos. In Especificaciones técnicas generales de materiales y construccion para proyectos de infraestructura víal y de espacio público para Bogotá D.C.

Instituto Nacional de Vías de Colombia. (2007). Manual de diseño de pavimentos asfálticos para vías con bajos volúmenes de tránsito.

Instituto Nacional de Vías de Colombia. (2008). Guía metodológica para el diseño de obras de rehabilitación de pavimentos asfálticos de carreteras. 
Instituto Nacional de Vías de Colombia. (2013). Artículo 461-Reciclado de pavimento asfáltico en frío en el lugar empleando ligantes bituminosos. In Especificaciones generales de construcción de carreteras de Colombia.

Instituto Nacional de Vías de Colombia. (2015). Manual de diseño de pavimentos asfálticos en vías con medios y altos volúmenes de tránsito. https://doi.org/10.3923/ijss.2017.32.38

Jiménez, M. (2009). Implementación del ensayo de módulo resiliente en bases granulares para pavimentos- Informe final. Retrieved from https://www.lanamme.ucr.ac.cr/repositorio/handle/50625112500/1207

Leal, M. (2010). Relación entre el módulo resiliente hallado por retrocalculo y el encontrado en ensayos de laboratorio. Universidad Nacional de Colombia.

Meza, M. (2008). Aplicación de la guía de diseño de pavimentos flexibles AASHTO 2002 a las condiciones colombianas. Universidad del Cauca.

Minguela, J. (2011). El estudio del comportamiento de los firmes reciclados in situ con cemento. Universidad de Burgos.

Montejo, A. (2006). Ingeniería de pavimentos. Bogotá: Universidad Católica de Colombia.

Morales Cárdenas, P. J., Chávez Arévalo, O., \& López Poveda, L. (2009). Efectos de la alta compactación de la capa de base en pavimentos flexibles.

Puppala, A. J., Hoyos, L. R., \& Potturi, A. K. (2011). Resilient Moduli Response of Moderately Cement-Treated Reclaimed Asphalt Pavement Aggregates. Journal of Materials in Civil Engineering, 23(7), 990-998. https://doi.org/10.1061/(ASCE)MT.1943-5533.0000268

Rodriguez, B. (2013). Análisis comparativo de métodos de diseño de pavimentos flexibles. 
Romeo, E., Orazi, M., Orazi, U., Accardo, C., Noto, S., \& Tebaldi, G. (2019). Evaluation of "long-term behaviour under traffic" of cement treated mixture with RAP. Construction and Building Materials, 208, 421-426. https://doi.org/10.1016/j.conbuildmat.2019.03.045

Rondón, H., \& Lizcano, F. (2007). Comportamiento resiliente de materiales granulares en pavimentos flexibles: Estado del conocimiento. Revista Ingenierías Universidad de Medellin, 6(5), 65-90.

South Afrian National Roads Agency LTD. (2013). South African Pavement Engineering Manual: Pavement Design. In South African Pavement Engineering Manual.

Wirtgen gmbH. (2016). El mudo de las recicladoras en frì y de las estabilizadoras de suelos de Wirtgen. Wirtgen Wroup.

Wirtgen GmbH. (2004). Wirtgen manual de reciclado en frío. Wirtgen Wroup. 